\title{
Extreme temperature events on the Iberian Peninsula: Statistical trajectory analysis and synoptic patterns
}

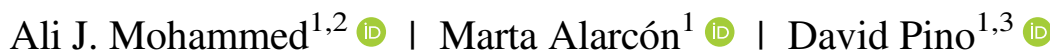

${ }^{1}$ Departament de Física, Universitat Politècnica de Catalunya, Barcelona, Spain

${ }^{2}$ Department of Atmospheric Sciences, College of Science, Al-Mustansiriya University,

Baghdad, Iraq

${ }^{3}$ Institute of Space Studies (IEEC-UPC),

Barcelona, Spain

Correspondence

Marta Alarcón, Departament de Física, Universitat Politècnica de Catalunya, Avda. Eduard Maristany 10-14, Barcelona 08019, Spain.

Email: marta.alarcon@upc.edu
The occurrence of heat waves and cold spells has been receiving special attention in recent years due to their impact on human health, ecosystems and other aspects, such as the economy. The present work uses a Lagrangian approach to analyse the physical processes leading to temperature extremes in the Iberian Peninsula (IP) for the 20-year period 1994-2013. Principal component analysis has also been carried out to identify the associated synoptic scale configurations. Spatial pattern analysis shows that the highest temperatures during hot events are reached in the SW region and the lowest ones in the NE, while a latitudinal gradient of $26 \mathrm{~K}$ was obtained for the cold events, with the lowest values in the NE regions and the Pyrenees. Most of the extremes persisted between 1 and 3 days for both hot and cold events. Rather than meridional advection, the primary cause behind the occurrence of hot extremes seems to be progressive diabatic warming, which becomes accentuated in its final stage and is caused, on the one hand, by air masses with long residence times over the IP and, on the other hand, by recirculation processes during summer days of weak baric gradient. The air masses producing the extreme cold events have faster trajectories and mainly originate in north and northeast Europe, due to a relative low in the central Mediterranean and a blocking high in the North Atlantic and/or in northeast Europe.

\section{KEYWORDS}

back trajectories, hot/cold events, Iberian Peninsula, principal component analysis, synoptic patterns, western Mediterranean

\section{1 | INTRODUCTION}

The globally averaged combined land and ocean surface temperature data, as calculated by a linear trend, indicates $0.85{ }^{\circ} \mathrm{C}$ of warming over the period $1880-2012$ (IPCC, 2013). However, in the context of climate change, there is evidence that not only the mean temperature but extreme temperature episodes are also changing in response to anthropogenic radiative forcing (Katz and Brown, 1992; Frich et al., 2002; Della-Marta et al., 2007; Dankers and Hiederer, 2008). Episodes of extreme temperature can affect many aspects of human life, such as death rates, physical comfort, environment, agriculture and hydrology (Schindler, 1997; Cooney, 2012; Harsant et al., 2013; Kebede et al.,
2015). Significant efforts have been made over recent years to assess changes in temperature as well as in frequency, intensity and duration of heat/cold waves (Frich et al., 2002; Brunet et al., 2007; Bieli et al., 2014). Alexander et al. (2006) analysed temperature data from stations located primarily in North America, Eurasia and Australia for the period 1951-2003, and found that over 70\% of the globally sampled land area showed a significant decrease in the annual occurrence of cold nights and a significant increase in the annual occurrence of warm nights. Other studies have analysed extreme temperatures in Europe at different spatial scales, ranging from regional to global (Schönwiese and Rapp, 1997; Luterbacher et al., 2004: Efthymiadis et al., 2011). In general, most of these results have revealed a 
significant upward trend in frequency and duration of hot extremes (Alexander et al., 2006). Della-Marta et al. (2007) have analysed daily maximum temperature series in Western Europe over the period 1880-2005, and they concluded that the length of summer heat waves has doubled while the frequency of hot days has almost tripled. Another result obtained in this study is that mean temperature change was higher over southern Europe and the Iberian Peninsula (IP), whereas mean temperature change was lower over central Western Europe.

The IP is one of the European areas where the projections show a large change in temperature. Dankers and Hiederer (2008) concluded that there is an increase in the daily mean temperature over most European regions, especially in the IP and the Alps. Some authors have analysed the trends of mean temperatures in the IP (Serra et al., 2001; Brunet et al., 2007; Del Río et al., 2011). However, little research has been conducted so far on extreme temperatures. Regarding this subject, the work of Fernández-Montes et al. (2013) analysed extreme temperatures in the IP in relation to circulation types. They concluded that the detected decrease in spring cold nights could be attributable to a decrease in the frequency of the northerly flows and that the increase in summer warm nights in the southern regions may be due to uptrends in the Iberian thermal low and North Atlantic Anticyclone. Furió and Meneu (2011) studied the statistical behaviour of extreme temperature values in four Spanish localities, concluding that the maxima (minima) temperatures are becoming more (less) extreme, and that, in general terms, the daily temperature range decreased over the 20th century. Brunet et al. (2007) studied the annual changes of maximum, minimum and mean temperatures over Spain from 1901 to 2005 and they found general and highly significant warming on an annual and seasonal basis over the entire period for the three daily temperature variables. In the same study, estimated trends in the number of moderately extreme cold days (TMAX $<10$ th percentile) and moderately extreme cold nights (TMIN $<10$ th percentile) showed significant reductions of, respectively, 0.74 and 0.54 days/decade. A regional study for Andalucía (Southern Spain) corroborates that maximum temperatures have increased along with the number of warm days and nights during the second half of the 20th century, particularly in summer (Castro-Díez et al., 2007).

Extended periods of cold temperatures in Europe during winter are generally of dynamic origin (Cattiaux et al., 2012). High-pressure anomalies over the Arctic and low pressure over the European continent induce the advection of cold air from the north or the northeast towards lower latitudes (Tomassini et al., 2012; Horton et al., 2015). In Peninsular Spain, an analysis (Prieto et al., 2004) based on an objective detection scheme was applied to 45 temperature stations for the period 1955-1998, and it revealed that most of the temperature extremes occurred under six synoptic patterns. However, they note that the role of synoptic processes was limited: they provide favourable conditions for its occurrence, but do not completely determine it. The study also detected a shift towards higher mean values in the distribution of minimum daily temperatures.

The IP is located in the transition zone between the mild, wet domain of the mid-latitudes and the dry area of the tropical anticyclone belt, and it is therefore especially sensitive to climate change. Temperature distribution in the IP is highly influenced not only by its complex orography, which can block or channel the movement of the air masses (Millán et al., 1991), but also by the proximity of the relatively warm waters of the Mediterranean Sea and the Atlantic Ocean. August is the hottest month for the Cantabria coast in the north, the Mediterranean in the east and south and the Gulf of Cádiz in the southwest; this is due to the influence of the sea, which delays the moment when the highest mean temperature is reached. In the rest of the territory, the hottest month is July, while the coldest one is January. The three main synoptic systems influencing the climate of the IP are: the subtropical high-pressure system, the winter RussianBaltic anticyclone, and the Saharan depression (Tullot, 2000). Among them, the most determinant is the first one, commonly known as the Azores anticyclone, which is centred during winter over this archipelago and extend to northern Africa. In summer, it is reinforced and displaced to the north. On the other hand, the variations in the Saharan depression have a direct influence on the occurrence of North African air-mass intrusions over the IP. Regarding the Russian-Baltic anticyclone, its western displacements determine the entrance of continental cold air masses in winter. Other significant synoptic centres are the Ligurian, the Gulf of Cádiz and the Icelandic lows because of the role they play in the Western Mediterranean Oscillation (WeMO, MartínVide and López-Bustins (2006)) and the North Atlantic Oscillation (NAO) teleconnections.

Because of the intense surface heating over land, a near stationary thermal low is produced in the IP mostly during the summer months reaching its maximum intensity during the afternoon and then weakening during the night (Hoinka and Castro, 2003). The physical process that generates the Iberian thermal low is the vertical expansion of the lowest layers of the atmosphere as a result of convective heating, which produces divergence above these layers (Hoinka and Castro, 2003). Strong pressure gradients develop at the boundary of the low, causing low-level winds that blow from the coastal areas towards the interior of the IP (Millán et al., 1991).

It is known that extreme temperatures in Western Europe can be produced by extreme phases of low-frequency variability patterns such as the NAO and the Arctic Oscillation (AO) (Pfahl and Wernli, 2012). The winter season of 2009-2010 was one of the coldest and snowiest in central North America and Northwestern Europe for decades, and it 
was suggested that this was a result of the extremely negative phase of the NAO (Jung et al., 2011). Favà et al. (2016) found significant positive correlations between summer $\mathrm{NAO}$ and the maximum temperatures for the northern IP for the period 1951-1967; while these correlations during the period 1962-1978 were negative and affected the eastern part of the IP. Other authors (Rodríguez-Puebla et al., 2010) pointed out no correlations between NAO and the occurrence of warm days in the IP. The relationship between the winter temperature variability over northern Spain and the climatic variability patterns of the NAO, AO and EastAtlantic Oscillation (EAO) were analysed by Sáenz et al. (2001). The only significant correlation was obtained for the EAO, while the NAO and AO did not show any significant correlation.

On the other hand, WeMO was introduced by MartínVide and López-Bustins (2006) to account for some Western Mediterranean regions that are either weakly related or not related at all to the NAO pattern, which is the case of the eastern IP. The WeMO is defined by using the dipole San Fernando (Spain)_Padua (Italy). The positive mode corresponds to high pressures over the Azores and SW IP and low pressures in the Liguria Gulf. In the positive phase, rainfall is more abundant on the Cantabrian peninsular coast and lower on the Mediterranean one. Its negative mode is produced when an anticyclone is situated in central Europe and the north of Italy while there are low pressures in the SW IP. The WeMO positive phase has been shown to trigger air masses into moving from the Atlantic into the IP, while its negative phase is associated with flows from the Mediterranean (Martín-Vide and López-Bustins, 2006; López-Bustins et al., 2008). Some studies have focused on the precipitation (Vicente-Serrano et al., 2009); however, few studies deal with the influence of the WeMO on IP temperatures.

This work focuses on the study of extreme hot and cold episodes in the IP for the 20-year period 1994-2013, based on the 12-hr maximum/minimum temperatures at $2 \mathrm{~m}$ height from the ERA-Interim reanalysis data (European Centre for Medium-Range Weather Forecasts, ECMWF). The conductive meteorological conditions have been characterized using: (a) a Lagrangian approach to determine the air-mass pathways; (b) the study of the evolution of the physical variables along the atmospheric trajectories and (c) the identification of the synoptic situations by principal component analysis (PCA) of the pressure and geopotential fields.

\section{2 | METHODS}

\section{1 | Meteorological data}

The study used the following data: ECMWF ERA-Interim 12-hr (03 and 15 UTC) maximum/minimum $2 \mathrm{~m}$ height temperature $(\mathrm{T} 2 \mathrm{MAX} / \mathrm{T} 2 \mathrm{MIN})$ in a $1^{\circ} \times 1^{\circ}$ grid covering the
IP, from $36^{\circ} \mathrm{N}$ to $45^{\circ} \mathrm{N}$ and from $9^{\circ} \mathrm{W}$ to $3^{\circ} \mathrm{E}$, with a total of 13 by 10 cells. At each grid point, hot/cold extremes were defined as those events in which T2MAX/T2MIN was above/under its 99.9 th/ 0.1 th percentile for the 20 -year period 1994-2013. This yielded 15 hot/cold extremes at each grid point, with a total of 130 grid points and a total of $1950 \mathrm{hot} /$ cold extremes in the domain.

The persistence of extreme events was analysed separately for diurnal (15 UTC) and nocturnal (03 UTC) extremes by applying the criterion of the 99.9th/0.1th percentile to the T2MAX/T2MIN database. Duration was then obtained by counting the number of consecutive days with temperatures in the 99.0th /1.0th percentile following and/or preceding each diurnal and nocturnal extreme.

The indices for the NAO (available at https:// climatedataguide.ucar.edu/climate-data/hurrell-north-atlantic -oscillation-nao-index-station-based; Hurrell et al., 2013), the WeMO (available at http://www.ub.edu/gc/2016/06/08/ wemo/; Group of Climatology, University of Barcelona) and the AO (available at http://www.cpc.ncep.noaa.gov/products/ precip/CWlink/daily_ao_index/ao.shtml; National Oceanic and Atmospheric Administration (NOAA)/National Center for Environmental Prediction (NCEP), Climate Prediction Center) were correlated with the annual number of extremes and the annual extreme temperature average. Standardized data (obtained by subtracting the mean and dividing it by the $S D$ ) were used for the extremes and the climatic indices. The Spearman rank correlation coefficient, the Kendall-tau and the Pearson coefficient were computed to measure the relationship between extremes and climatic indices. Considering that the climatic indices show their most relevant dynamics during the cold months, both the annual and the winter (December-March) NAO, AO and WeMO indices were used as well as the summer NAO, which is defined as the leading mode of July-August sea level pressure variability in the North Atlantic sector (Bladé et al., 2011).

\section{2 | Back trajectories}

A Lagrangian approach was applied by computing backward trajectories to identify the origin and pathway of the extreme air masses. The Hybrid Single-Particle Lagrangian Integrated Trajectory model (HySplit-4) of the NOAA (available at http://www.arl.noaa.gov/ready/hysplit4.html, Draxler and Rolph, 2003) was used to compute 10-day iso- $\sigma$ back trajectories from the gridded NCEP/National Center for Atmospheric Research (NCAR) reanalysis data. Sigma vertical coordinate was chosen because this option eliminates the problem of intersecting the ground, which affects other vertical coordinate systems such as the isentropic system. Trajectories were computed at two vertical levels: 100 and 1,500 $\mathrm{m}$ above sea level (a.s.1.), at the time of episode onset. These heights can be taken as representative of the mean atmospheric transport at a synoptic scale within the lower and upper boundary layers (Izquierdo et al., 2014). Stohl 
(1998) discussed some of the limitations of trajectory analyses concluding that the path of an air parcel along a trajectory is in general sensitive to the following: the initial conditions of the model data, uncertainties in the wind field used to calculate air parcel motions, and interpolation related to model resolution. Errors of $20 \%$ of the distance travelled seem to be typical for trajectories computed from analysed wind fields.

Several of the extremes occurred on consecutive days at a given grid point. In these cases, only the first day of the extreme was considered in order to focus on the mechanism leading to the extreme production. By considering only the first day of consecutive extremes, the number of extreme events was reduced from 1,950 to 1,275 for hot events and to 1,239 for cold events.

In order to understand the dynamics of the air masses leading to temperature extremes, a set of variables was considered along with the back trajectories: latitude, longitude, height, pressure, temperature, potential temperature, relative humidity, mixing-layer height and downward solar radiation flux. These variables determine the location and height of the air mass at a given time step, as well as its thermodynamic properties: temperature changes caused by heating/ cooling during diabatic/adiabatic vertical displacements, radiative processes, humidity changes and surface heat fluxes. In order to provide a measure of the deviance of an air-mass property from its final state, their evolution along the back trajectories were analysed in terms of differences regarding their final value at the grid point, except for mixing-layer height and downward solar radiation. To follow the temporal changes, five percentiles of the variables were traced along the trajectories: the median (50th), the upper and lower quartiles (75th and 25th) and the 5th and 95th percentiles. The physical variables are obtained as an optional output of HySplit-4. The data are retrieved from the Global Forecast System model and interpolated to the coarser grid of the trajectories. As a consequence, there is a certain degree of uncertainty in adopting these thermodynamic values.

\section{3 | Synoptic situation}

The meteorological scenarios causing extreme hot/cold episodes in the IP were characterized using PCA of the mean sea level (m.s.l.) pressure and the geopotential height at 850 and $700 \mathrm{hPa}$. ERA-Interim reanalysis data were used, with $2^{\circ} \times 2^{\circ}$ horizontal resolution in a domain covering Europe, the Mediterranean Sea and northern Africa $\left(30^{\circ} \mathrm{W}-\right.$ $30^{\circ} \mathrm{E}, 20^{\circ} \mathrm{N}-70^{\circ} \mathrm{N}$ ). Several extremes occurred on the same date at different grid points or on consecutive days on the same grid point. These dates were filtered out and PCA was applied to the 140 remaining dates in S-mode (correlation between temporal series) and T-mode (correlation between fields). In S-mode, the grid points are the variables and the dates are the cases; whereas it is vice versa in T-mode. Smode tries to identify homogeneous m.s.l. pressure and geopotential regions with respect to time variability. T-mode extracts the spatial variability and the dominant circulation types (Huth, 1996; Compagnucci et al., 2001). PCA was carried out using the correlation matrix.

\section{3 | RESULTS AND DISCUSSION}

\section{1 | Annual distribution, duration and correlation with climatic indices}

Figure 1 shows the average of extreme temperatures at each grid point. This spatial distribution reflects the strong influence of the three main geographical factors in IP: orography, sea proximity and latitudinal difference. The highest values for the hot events corresponded to the SW region and the lowest ones to the NE (Pyrenees) corner, with a difference (a)

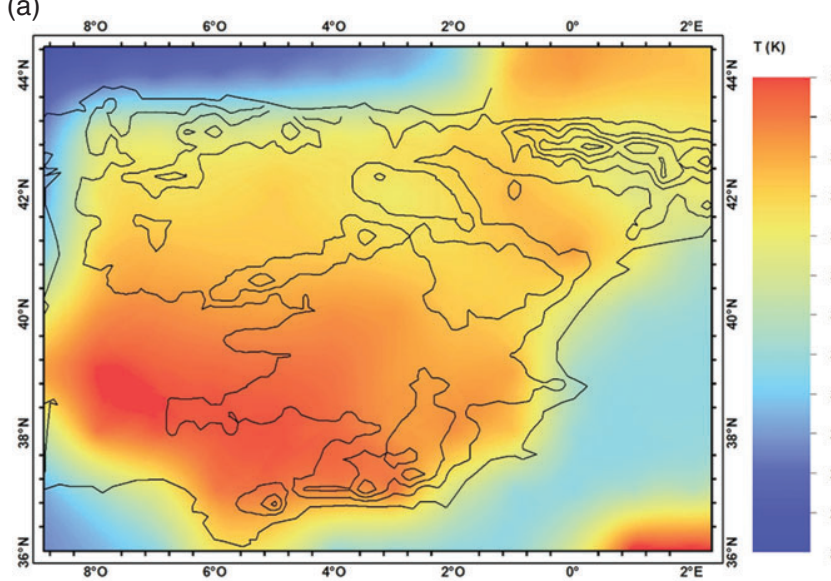

(b)

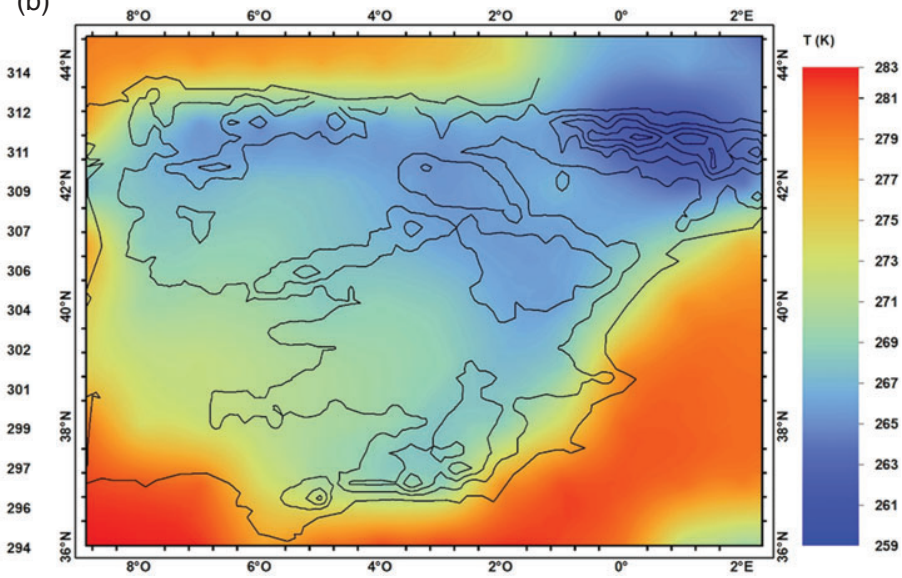

FIGURE 1 Geographical distribution of the average extreme temperatures for the 20-year period at each grid point: (a) extreme hot events and (b) extreme 
(a)

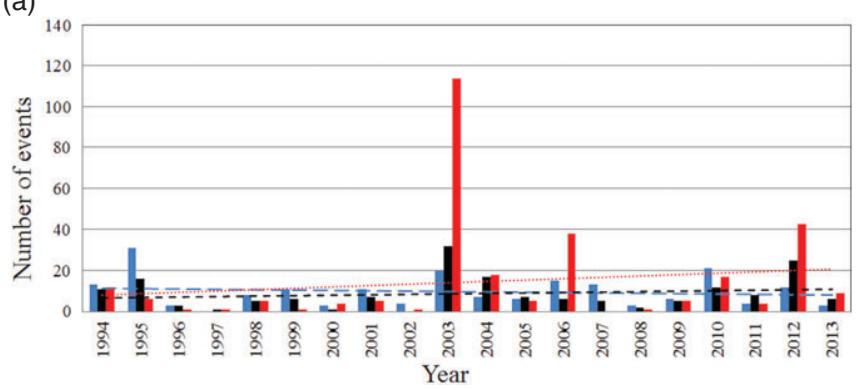

(c)

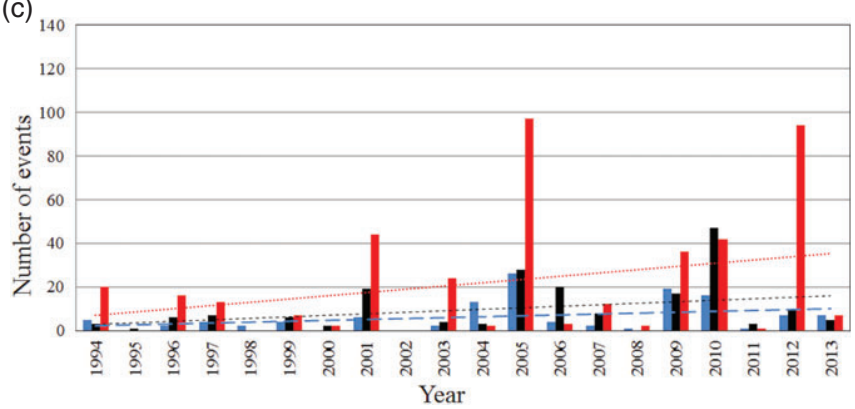

(b)

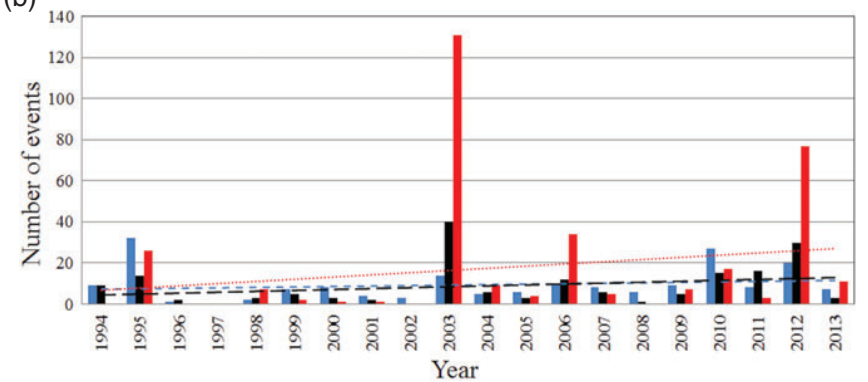

(d)

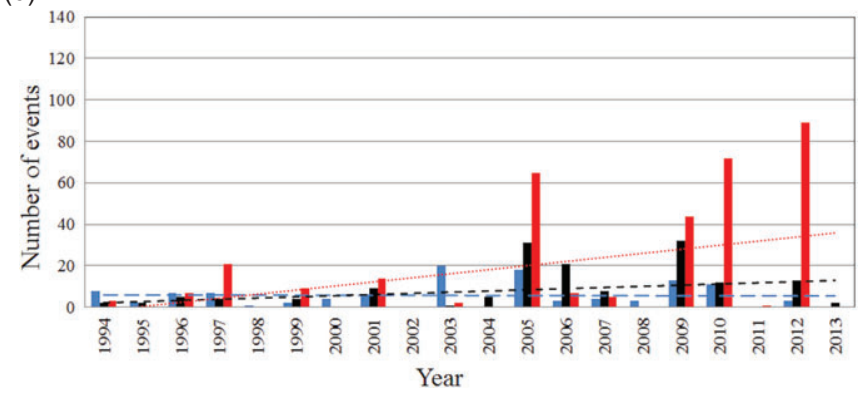

FIGURE 2 Number of events with durations of 1 day (blue), 2 days (black) and 3 or more days (red) for (a) hot nocturnal (0300 UTC), (b) hot diurnal (1500 UTC), (c) cold nocturnal and (d) cold diurnal. The dashed lines represent the trend for each duration

between them of about $8 \mathrm{~K}$ inside the continent and $20 \mathrm{~K}$ in the whole domain. Regarding the cold events, a latitudinal gradient of $22 \mathrm{~K}$ can be observed from the northeast to the southwest, with the lowest values in the Pyrenees.

Figure 2 indicates the temporal evolution of the number of events with durations of one, two and three or more days, specifically those that are: (a) hot nocturnal (0300 UTC) events, (b) hot diurnal (1500 UTC) events, (c) cold nocturnal events and (d) cold diurnal events, with the trend lines also represented. Regarding the hot events, two periods can be distinguished: from 1996 to 2002 only 19\% of events occurred, while the second half of the period (2003-2013) registered $81 \%$. The year 2003 registered the highest number (30\%). Regarding the cold events, the 10 first years of the period registered only $28 \%$ of the events, while the second half of the period comprised $72 \%$. The year 2005 registered the highest number of cold events, representing $21 \%$ of the total, followed by 2012 with $20 \%$.

Most of the extreme hot events ( $80 \%$ for nocturnal and $70 \%$ for diurnal) persist between 1 and 3 days (Figure 3a), with durations of 1 day being the most frequent. The longlasting episodes of more than 9 days correspond to the extremely hot summer in the year 2003, with the exception of four that occurred in other years. The years 2003, 2010
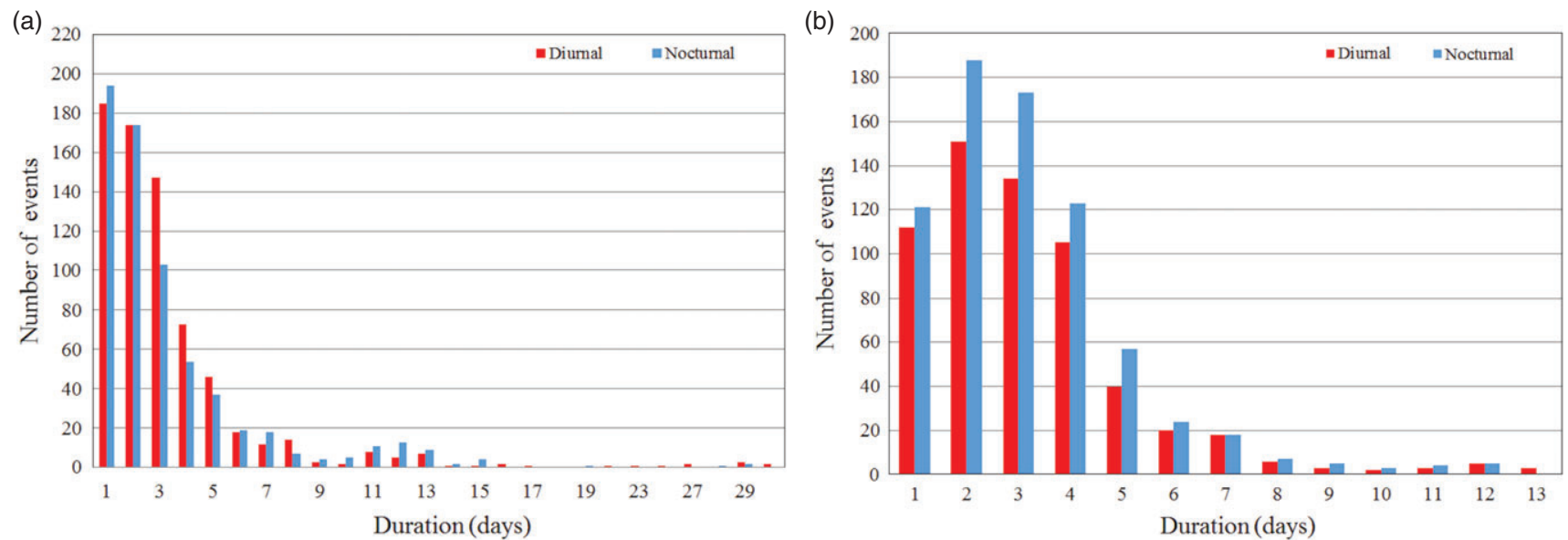

FIGURE 3 Duration for diurnal (red) and nocturnal (blue): (a) extreme hot events and (b) extreme cold events 
and 2012 accumulated a total of 20 long episodes (three or more days) that affected the IP in at least $10 \%$ of its territory. The temporal trend in the occurrence and persistence of hot events is positive, but not significant. This result is in agreement with that obtained by Brunet et al. (2007) for a longer series (the 105-year period 1901-2005) and moderately hot days ( $\mathrm{T}>90$ th percentile), in which they obtained a positive significant trend of 0.53 days/decade.

About $80 \%$ of the cold events persisted between 1 and 3 days, with 2-day durations being the most frequent, followed by 3-day durations. Episodes of up to 13-day durations were recorded (Figure 3b), but all the episodes of more than 9 days were registered in 2012, with the exception of two cases. A significant positive trend $(p \leq 0.1)$ of 26.1 days/decade ( 0.2 days/decade per grid point) for diurnal events and 27.6 days/decade $(0.21$ days/decade per grid point) for nocturnal events has been obtained. The persistence of cold events also shows an increasing trend, intensified in the last years. This upward trend is in consonance with the more general conclusion that there is no apparent trend towards fewer extreme cold events on either continent, which was observed by Walsh et al. (2001) for the 1948-1999 record. However, our result differs from the above-mentioned work by Brunet et al. (2007), in which a negative trend was obtained in the IP, probably due to the different length of the analysed periods.

The Spearman rank, Kendall's tau and the Pearson's correlation were applied for detecting whether the climatic indices correlated in any way with the number of extreme events as well as with the annual average extreme temperature for all the grid points. No significant correlations were found between the number of hot days and NAO, AO, WeMO (annual and winter indices) and summer NAO (not shown). On the other hand, a significant positive correlation ( $p$ $<.01$ ) was found between the annual average of the extreme hot temperatures and annual WeMO (Kendall: 0.328; Spearman: 0.455).

Regarding the cold events, a significant $(p<.01)$ negative correlation was found between the number of cold days and the annual indices for NAO (Kendall: -0.345; Spearman: -0.502; Pearson: -0.429) and AO (Pearson: -0.415). However, no correlation was found with WeMO. On the other hand, neither were any significant correlations found between the annual indices and the annual average of the extreme cold temperatures. Several studies have focused on the influence of climatic indices in precipitation over the IP; however, little has been done so far with temperatures and extreme temperatures. Nevertheless, because NAO modulates the intensity of westerlies into Europe, negative values of the NAO index have been considered as features common to European cold outbreaks (Walsh et al., 2001). According to our results, the number of days with extreme cold temperatures in the IP would decrease (increase) in years with positive (negative) phases of NAO or AO. This is in concordance with the lower cyclone frequency, less cloud cover and, therefore, the greater insolation in the western Mediterranean region that is attributed to a positive NAO phase (Hurrell et al., 2013). This is also in accordance with the result obtained for hot events showing higher (lower) extreme temperatures in years with a positive (negative) WeMO phase, as WeMO affects the region in a similar way as NAO and AO. On the other hand, our results would differ from those of Rodrigo (2015), in which a significant increase in minimum winter temperatures under the negative phase of the NAO was found for the period 1956-2005. They explained this as a result of lower radiative cooling during the NAO negative phase resulting from greater cloudiness. On the other hand, El Kenawy et al. (2013) found a significant relationship between the negative phase of WeMO and maximum temperatures during the warm season in the northeastern region of the IP for the period 1920-2006. In contrast, they did not find any significant correlation for minimum winter temperatures. This disagreement with our results could be due to the different length of the analysed period and the fact that they focused on a specific region of the IP.

\section{2 | Trajectory density}

Back trajectories were computed, with origins on the grid points at the time of episode onset. The results indicate that cold-event trajectories were faster than those of hot events. With a median of $772 \mathrm{~km}$ at $100 \mathrm{~m}$ and $1,250 \mathrm{~km}$ at 1,500 $\mathrm{m}$ a.s.l., the travel distances of the trajectories 4 days before the hot events are clearly less than the corresponding median distances of 2,476 and 2,665 km, respectively, of the cold events. These differences also exist 10 days before the episodes, with a median of $2,255 \mathrm{~km}$ at $100 \mathrm{~m}$ and $2,600 \mathrm{~km}$ at 1,500 $\mathrm{m}$ a.s.l. for hot events, while for cold events they are, respectively, 4,315 and 4,357 km.

The pathway pattern and source regions associated with the air masses responsible for extreme events were analysed by superimposing a grid mesh of $1^{\circ} \times 1^{\circ}$ over the integration domain of the back trajectories and by computing the trajectory densities, that is, the number of back-trajectory time steps per grid box $\left(1^{\circ} \times 1^{\circ}\right)$. Densities were computed for 4- and 10-day length back trajectories at 100 and 1,500 $\mathrm{m}$ a.s.l. The 4-day length results are shown in Figure 4. No important meridional advection involving the production of hot extremes is observed. At $100 \mathrm{~m}$ (Figure 4a), the densities have a more marked Mediterranean component than at $1,500 \mathrm{~m}$ (Figure $4 \mathrm{~b}$ ), in which the densities are higher in the SW region of the IP. In general, most of the trajectories at the two levels remain within the IP region and its nearby surroundings during the days prior to the hot events, indicating that the local recirculation of warm air masses is mainly responsible for the high temperatures rather than the occasional entrance of North African air masses. The density map obtained for 10-day lengths is very 
(a)

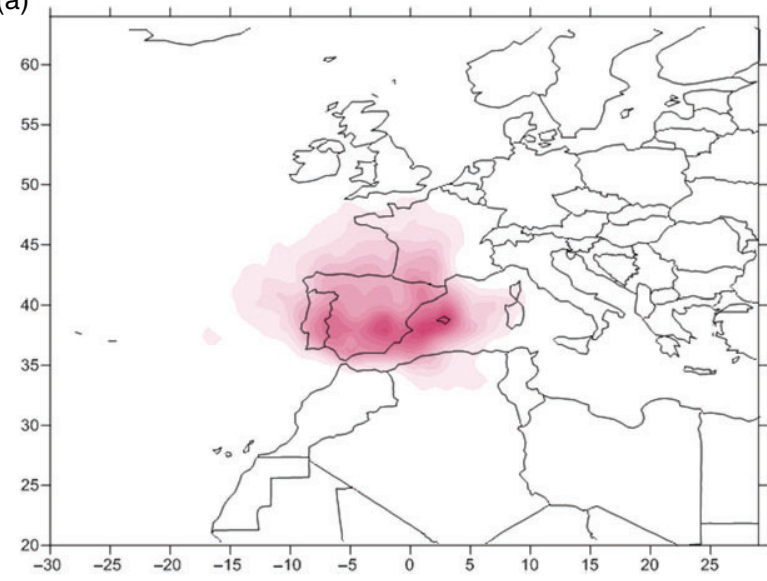

(c)

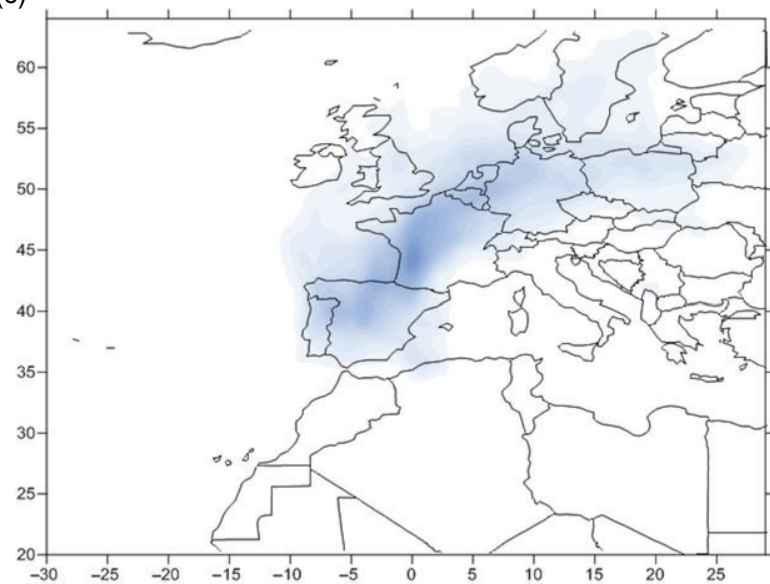

(b)

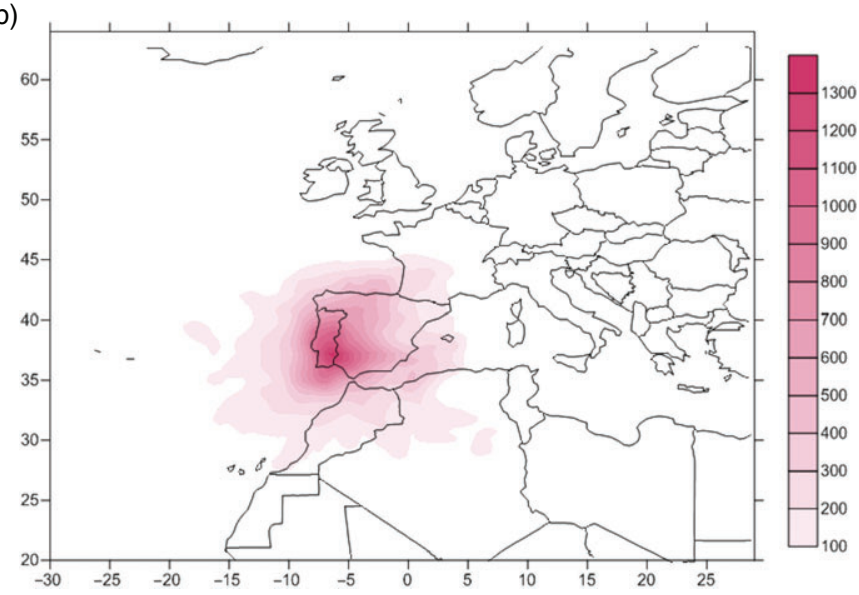

(d)

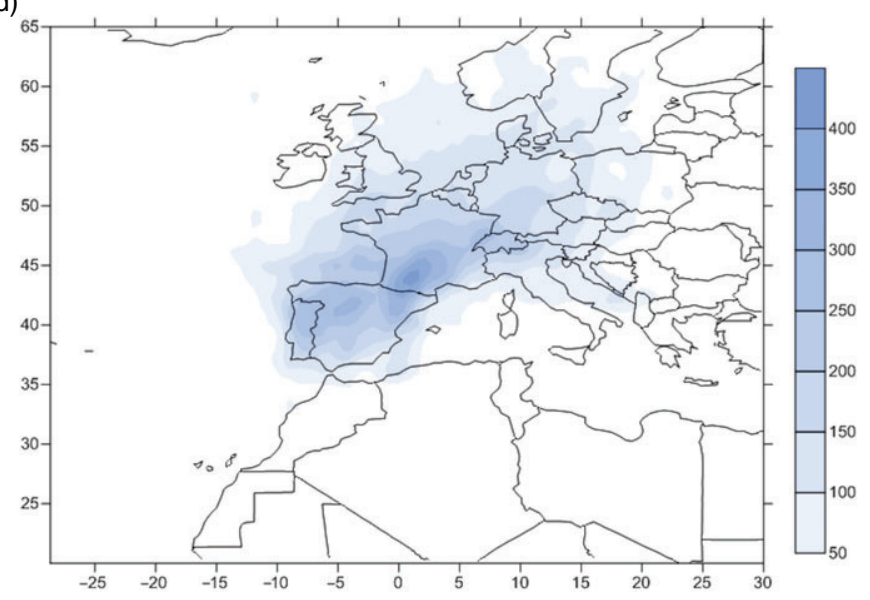

FIGURE 4 Trajectory density patterns (number of 1-hr time steps per grid box) for extreme hot events of 4 days at (a) $100 \mathrm{~m}$, (b) 1,500 m, and for extreme cold events of 4 days at (c) $100 \mathrm{~m}$, (d) $1,500 \mathrm{~m}$

similar (not shown here). Other studies (Millán et al., 1997; Jorba et al., 2004; Izquierdo et al., 2015) regarding the seasonal patterns of the atmospheric regimes in the IP showed similar results, which agree on the occurrence of predominantly slow-moving recirculation flows from the W and SW in summer. The meridional and zonal displacements at $100 \mathrm{~m}$ can be better appreciated in Figure 5, where the differences between the latitude and longitude at the origin and in the different time steps are represented for the median, the upper and lower quartiles, and the 5 th and 95 th percentiles. A latitudinal decrease of about $5 \mathrm{~K}$ is observed for the median, as well as a longitudinal decrease from west to east of $20 \mathrm{~K}$ (Figure 5a,b).

The extreme cold events are principally associated with a northeastern advection of air masses from central and northern Europe. Figure 4c,d shows the 4-day length trajectory densities at 100 and 1,500 $\mathrm{m}$ a.s.l. As in the case of hot events, the distribution of densities is similar to those of a 10-day length, which is not shown here. This figure indicates that the main flow through the NW European Atlantic coast comes from the Baltic regions at low levels while it has a more southerly component at high levels. The meridional and zonal displacements of the cold air masses along the trajectories are in general greater than for the hot air masses. Figure 5c,d represents the median, the upper and lower quartiles, and the 5th and 95th percentiles of the differences between the latitude and longitude at each time step and their respective origin values, at $100 \mathrm{~m}$ a.s.1. The longitudinal (from east to west) and latitudinal (from north to south) differences for the median are about $20 \mathrm{~K}$ in the 10 days of the back trajectories, indicating an advection of cold air masses from the Arctic and Scandinavia. The latitudinal shift is produced mainly in the 4 days before the cold events. This result is consistent with situations in which large "blocking" anticyclones over Scandinavia and Northwestern Russia drive easterly winds over Europe, which has been identified as an important synoptic-scale cause of winter cold spells (Croci-Maspoli et al., 2007; Cattiaux et al., 2010; Sillmann et al., 2011; Andrade et al., 2012).

\subsection{Evolution of the physical variables for hot events}

The evolution of the physical variables has been analysed along the $100 \mathrm{~m}$ height back trajectories. As in the previous 

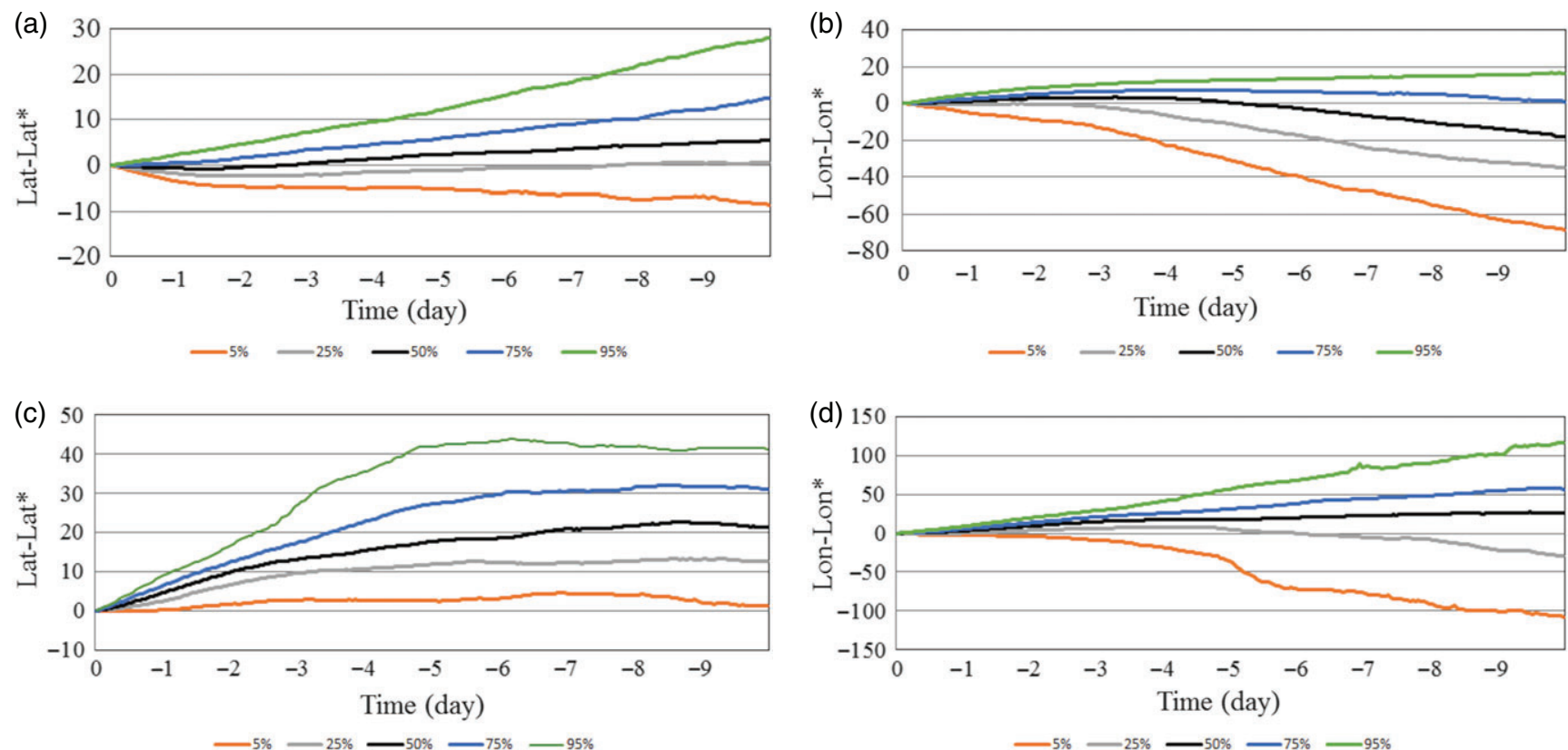

FIGURE 5 Meridional and zonal movement corresponding to the $100 \mathrm{~m}$ back trajectories of the air masses causing hot (a and b, respectively) and cold ( $\mathrm{c}$ and d) extreme events in the IP, in terms of differences regarding latitude and longitude at event origin (lat* and lon*). Black lines represent the median; grey and blue correspond to the upper and lower quartiles; and orange and green to the 5th and 95th percentiles, respectively

section, temperature and potential temperature are represented by the median, the upper and lower quartiles and the 5th and 95th percentiles of the differences between the values of the variables at each time step and their values at the time the extreme events were produced. Mixing-layer height, relative humidity and downward solar radiation have also been evaluated.

The analysis of the evolution of the temperature (Figure 6a) shows that there was a steady warming of the air mass along the trajectories, with a diurnal cycle that was more pronounced during the 3 days before the extremes. The temperature difference for the median in the 10 days was about $15 \mathrm{~K}$. The evolution of the potential temperature (Figure 6b) was similar, indicating that there was diabatic heating of the air mass due to the absorption of sensible heat from the ground on days of intense solar radiation. Figure $6 \mathrm{c}$ represents the evolution of the height, temperature and potential temperature for the median, where we can clearly see the parallel evolution and strong diurnal heating during the 3 days prior to the onset, during which the air mass recirculates above the IP, and thus leads to in situ heating due to the absorption of sensible heat from the ground.

The mixing-layer height (Figure 6d) remains near constant throughout the greater part of the path. However, in the 3 days leading up to the hot events, there is a progressive increase in its height and its diurnal cycle, indicating the greatest convection when the air mass enters the IP, 3 days prior to the events for the 95th percentile and 1 day prior for the median.
The evolution of relative humidity (Figure 6e) shows stable high values from days 10 to 7 before the onset of the extremes (median of near $80 \%$ ) and a progressive decrease from day 6 , which is more accentuated in the 2 days prior to the warm events when the air mass enters the IP and its humidity drastically drops to median values of $30-55 \%$. In accordance with back-trajectory densities, this suggests a maritime origin of the air mass and a prolonged stay above the sea in the west Mediterranean, Alboran Sea and Atlantic Ocean near Gibraltar, all of which probably favour sea/landbreeze development. Recirculation induced by the breeze occurs when air is carried landward by the sea breeze during daylight hours and seaward by the land breeze at night. If the coastal zone is a region of significant relative relief, as in the IP, topographically forced circulations interact with sea/land-breeze circulations to further obstruct large-scale air mass advection. In this case, the air mass advected shoreward by the sea breeze is eventually caught in upslope flows that enhance the sea-breeze strength. Breeze recirculation times are on the order of $24 \mathrm{hr}$ with a horizontal scale of approximately $130 \mathrm{~km}$ (Steyn, 1998). However, the spatial extent and intensity of the episodes can be reinforced by the diurnal development of the Iberian thermal low. A quasisteady downward solar radiation flux along the back trajectories occurs (Figure 6f), and this can be explained by the proximity between the regions that are crossed by the air masses.

In summary, the trajectory densities and the evolution of the physical variables indicate that the production of hot episodes is due to progressive warming caused by air masses of 

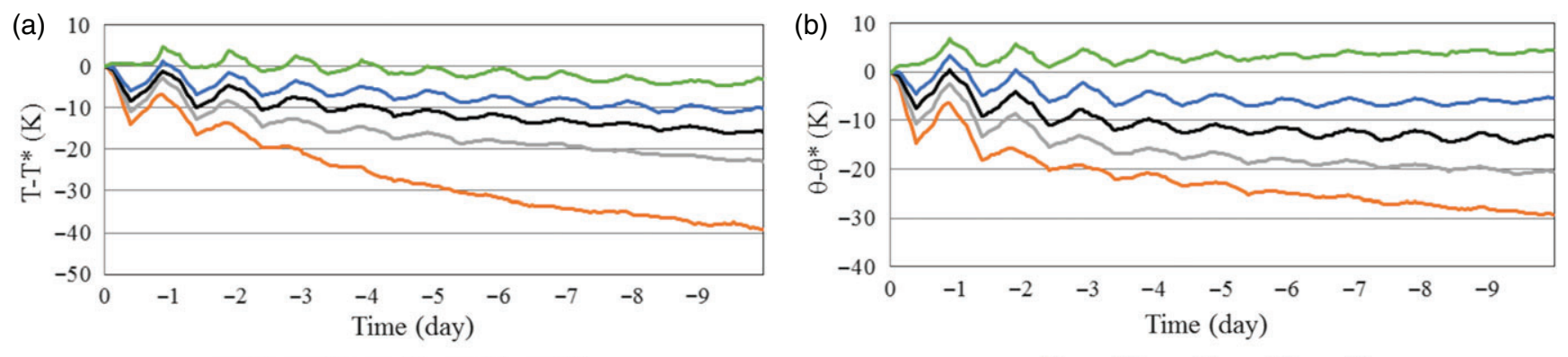

$-5 \%-25 \%-50 \%-75 \%-95 \%$
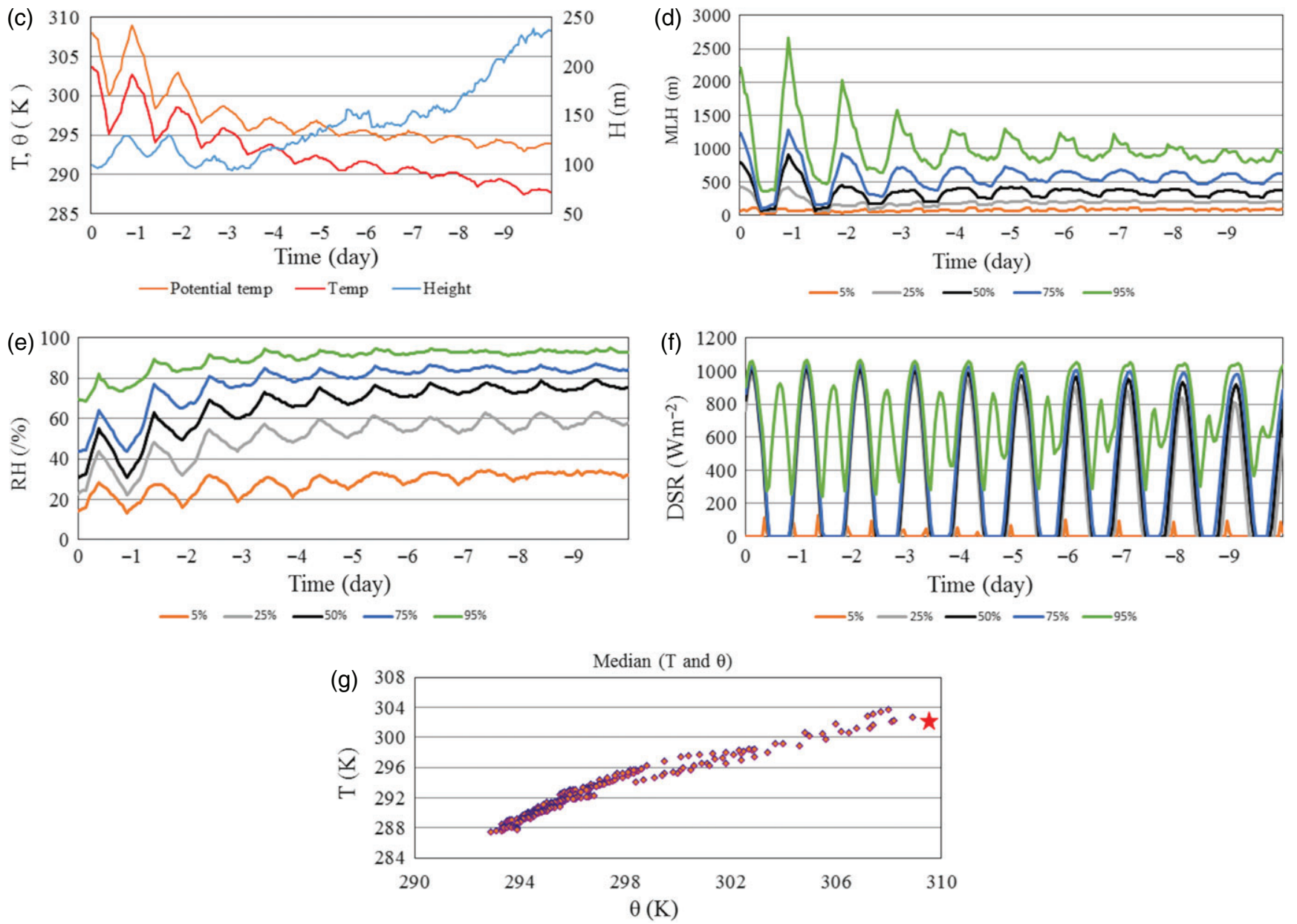

FIGURE 6 Evolution along the back trajectories of hot events at $100 \mathrm{~m}$ of (a) temperature and (b) potential temperature for hot extremes in terms of differences regarding the temperature and potential temperature at the origin. (c) Evolution of the median values of potential temperature ( $\theta$, in orange), temperature $(T$, in red) and height $(H$, in blue) for hot extremes. (d) Evolution of the mixing-layer depth, (e) relative humidity and (f) downward solar radiations for hot extremes. (g) Adiabatic and diabatic temperature change for hot extremes where each point represents the $T$ and $\theta$ median of the set of trajectories at each specific time step. The star indicates the values at time step 0. Colours in (a), (b), (d)-(f) as in Figure 5

long residence times over the IP during recirculation processes on summer days of weak baric gradient, rather than Saharan dry and warm air masses entering the IP from North Africa, which play a secondary role in producing hot extremes.

\section{4 | Evolution of the physical variables for cold events}

The temperature increases progressively along the trajectories during cold events, with a difference in the median of about $15 \mathrm{~K}$ over 10 days (Figure $7 \mathrm{a}$ ). The behaviour of the median potential temperature (Figure $7 b$ ) is different in two ways. First, it shows radiative cooling of about $5 \mathrm{~K}$ from days 10 to 3 before the extremes, when the air mass crosses Scandinavia and northern Europe; and, second, diabatic warming of about $3 \mathrm{~K}$ occurs in the 3 days prior to the events. The evolution of the median for height, temperature and potential temperature is represented in Figure $7 \mathrm{c}$, where it can be seen more clearly that the subsidence causes adiabatic heating by means of air mass compression. The 
warming is accentuated in the 2 or 3 days prior to the extremes, when the potential temperature also increases, suggesting diabatic heating of the air mass during its passage over the IP or its surrounding oceanic waters. Subsidence of several hundreds of hectopascals has been described as typical for trajectories of the coldest air that reach the surface in Europe's affected regions, with the source regions being over northern Asia (Walsh et al., 2001; Pfahl and Wernli, 2012). In our study, a median subsidence of $150 \mathrm{hPa}$ has been obtained for the 10-day back trajectories (not shown). This indicates that the air near the surface would have been even colder than it was if it were not for the adiabatic warming associated with the subsidence.

The evolution of the mixing-layer height shows (Figure 7d) a less marked diurnal cycle than in the warm extremes. From days 10 to 5 before the extreme, this oscillation is almost imperceptible for the median and becomes more accentuated 3 days prior to the events. The general trend is positive, showing an almost continuous increase from the start of the trajectories 10 days before the events. Lower values occur over northern Europe, which is associated with high latitudes and the influence of the cold north Atlantic waters, whereas higher values occur when the air mass travels over the IP due to the high topography and low soil moisture.

Relative humidity shows (Figure 7e) moderate values. There is a slight increase in the two first days of the path (days 9 and 10 before the events), which is probably due to contact with the Baltic and North Atlantic Ocean. In addition, the values remain almost constant in the central part of the path, where the air mass crosses continental Europe, followed by a new increase on the day prior to the extremes.

In contrast with hot events, the downward solar radiation flux for cold events (Figure 7f) exhibited low values, namely, zero in the case of the median for days 10 and 9 before progressively increasing as the back trajectories approached the IP, thus reflecting the high latitudes of origin for these air masses.

The evolution of the physical variables along the back trajectories indicates that the production of cold events is driven by mechanisms that are different from those driving hot ones. Air mass advection from northern European regions is the main process. The diabatic and adiabatic changes in temperature are represented through the evolution of the median temperature $(T)$ versus median potential temperature $(\theta)$. The hot events (Figure $6 \mathrm{~g}$ ) show progressive diabatic warming, which becomes more pronounced 3 days before onset (as indicated by the greater separation between points), with a total increase of $16 \mathrm{~K}$ along the path. Regarding the cold events, Figure $7 \mathrm{~g}$ shows diabatic radiative cooling with a decrease of about $4 \mathrm{~K}$ in the potential temperature during the first days of the path, when the air mass crosses the high latitude regions. Along this first part of the path, there is also adiabatic warming by subsidence of the air mass, with a final balance of $+6 \mathrm{~K}$. In the 3 days prior to onset, the adiabatic warming by subsidence continues and is still more pronounced, but it is also accompanied by a diabatic contribution of nearly $5 \mathrm{~K}$ as the air mass approaches the IP. The total temperature change in the median over these 10 days is $+16 \mathrm{~K}$. The westward migration of the European cold air masses has already been related (Walsh et al., 2001; Pfahl and Wernli, 2012) to the intensity of the eastward airflow reaching Europe from the North Atlantic, and the NAO index is a natural measure of this intensity.

\section{5 | Synoptic situation for hot events}

PCA in S-mode gives a spatial regionalization of the main characteristics of the time evolution of a variable (Compagnucci et al., 2001): m.s.l. pressure and 850 and $700 \mathrm{hPa}$ geopotential height, in our case. That is, it allows us to first isolate regions of grid points that covary similarly and, second, to identify regions that are homogeneous in terms of time variability. The first two principal components (PC1 and PC2) that were obtained here in S-mode represent $45 \%$ of the total cumulative variance for the m.s.l. pressure, and 40 and $35 \%$, respectively, for geopotential at 850 and $700 \mathrm{hPa}$. PC1 ( $25 \%$ of total variance) revealed a strongly positive temporal correlation with the time series of local m.s.l. pressure in central and southern Europe, extending to the West Mediterranean Sea and North Africa, while there was a weaker negative correlation in the Atlantic Ocean directly off the North African coast (Figure $8 \mathrm{a}$ ). The PC1 pattern correlations at 850 and $700 \mathrm{hPa}$ (Figure 8b,c) were similar, but showed a shift in which the positive correlations displaced southward and the negative to the northeast. The correlation pattern for PC2 (20\% of total variance) of m.s.l. pressure was positive in the North Atlantic Ocean facing France and extending to NW IP, while it was weakly negative in the East Mediterranean Sea and North Africa (Figure 8d). In the second component, the correlation pattern at 850 and $700 \mathrm{hPa}$ showed highly positive correlations in the northern regions and centred in the British Islands, while the correlations were negative in North Africa and the Mediterranean Sea (Figure 8e,f).

In T-mode, PCA analysis determines the main spatial types. The two first principal components obtained for hot events in T-mode represented $70 \%$ of the m.s.l. pressure total variance. The map of the loading values obtained for the first component (Figure 8g) shows a low-pressure system centred over North Africa. Frequent in summer, this system is of thermal origin and displaces the almost permanent North African anticyclone to upper levels (Figure 8h,i), causing a $\mathrm{SE}$ circulation in the central Mediterranean and southern IP at low levels. A ridge from the Atlantic anticyclone extends towards central Europe and drives a NW flow over the northern and western regions of the IP, blocking the entrance of Atlantic disturbances to the inner IP and Mediterranean. The Iberian thermal low, shaping up in the average m.s.l. pressure map (not shown here), remains stationary 

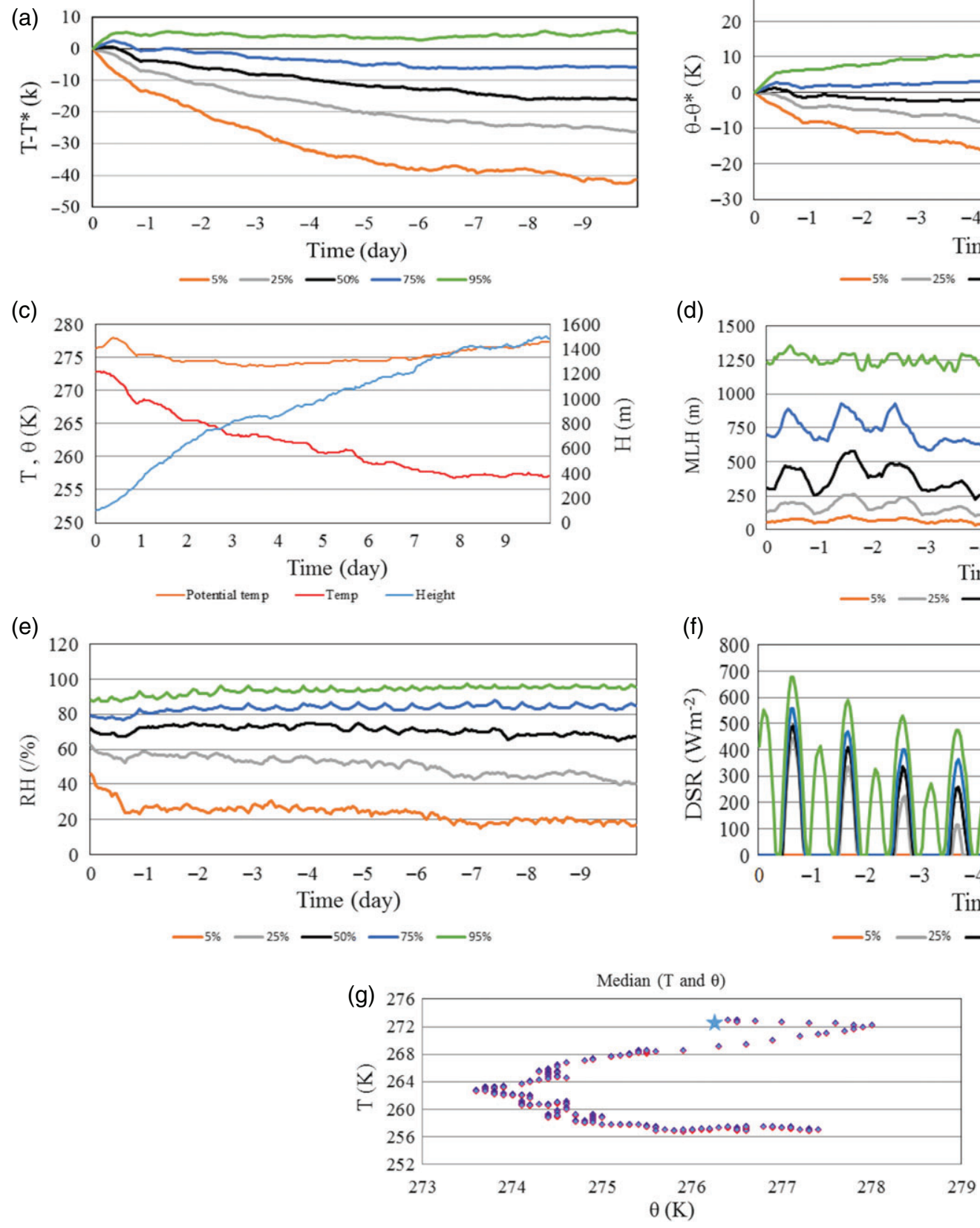

FIGURE 7 Same as Figure 6, but for cold events

over the area and increases blockage durations, leading to extreme warm episodes. The second component is related to a blocking situation, demonstrating the simultaneous presence of a deep low-pressure system over the south of Iceland and a high-pressure system over Scandinavia, inducing a null baric gradient in the IP, the Mediterranean Sea and North Africa (Figure 8j). This same situation is reproduced at 850 and $700 \mathrm{hPa}$ (Figure 8k,1).

The meteorological scenarios indicated by the two first principal components correspond to situations of atmospheric blocking, whose strong linkage with warm temperature extremes over mid latitude regions in the Northern Hemisphere has already been suggested by Pfahl and Wernli (2012). These summer blocking situations, characterized by
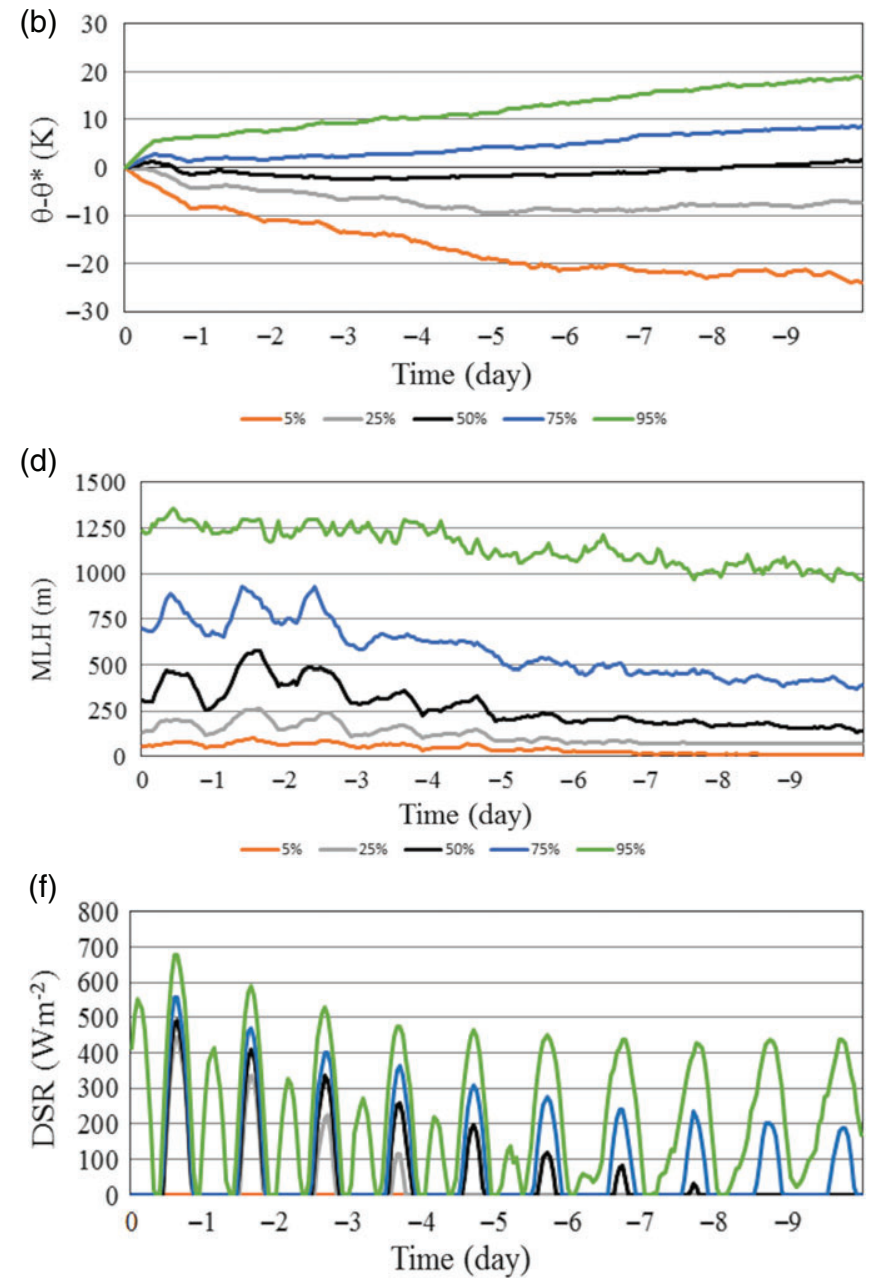

$-5 \%$ - $25 \%$ - $50 \%$ - $75 \%$ - $95 \%$ 
(a)

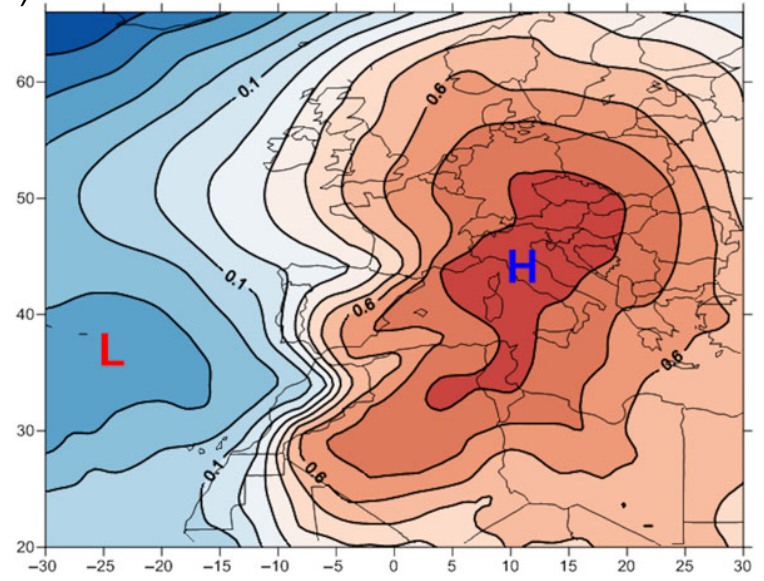

(c)

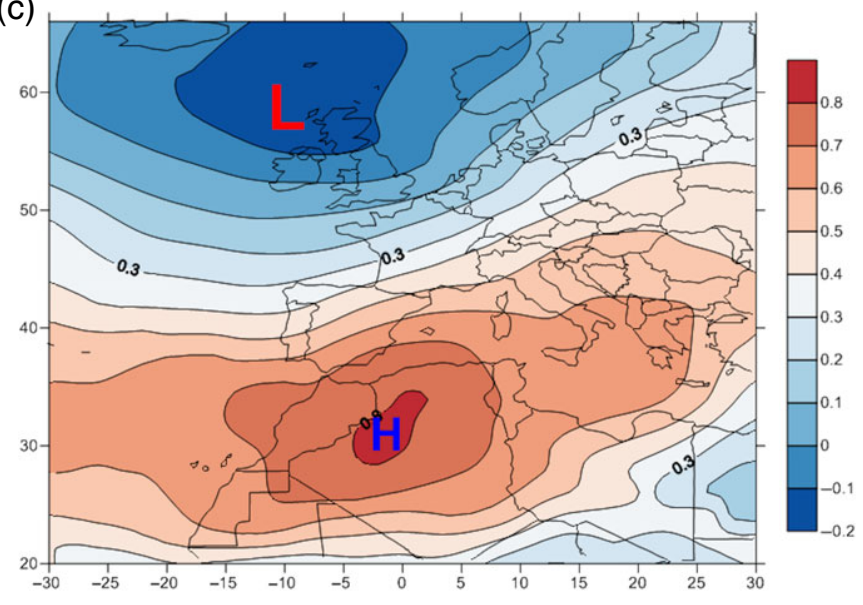

(e)
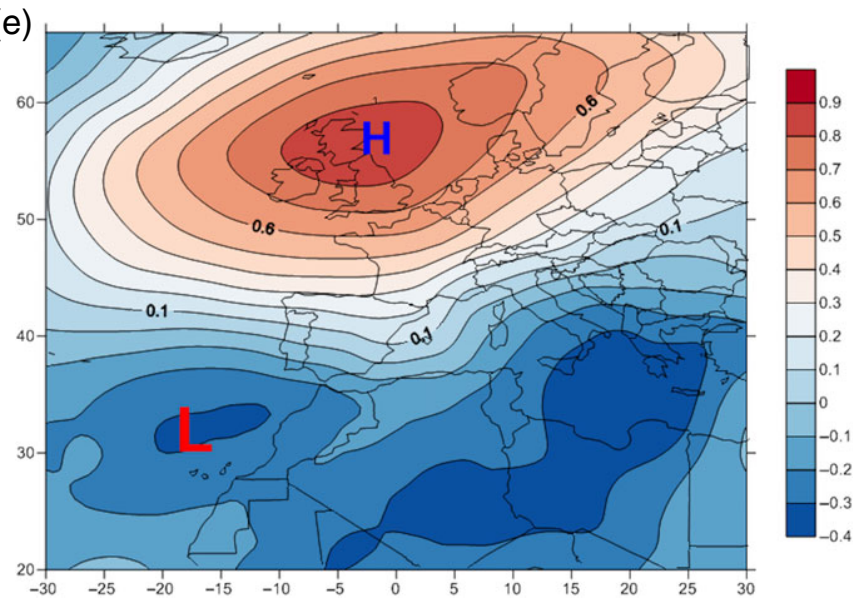

(b)

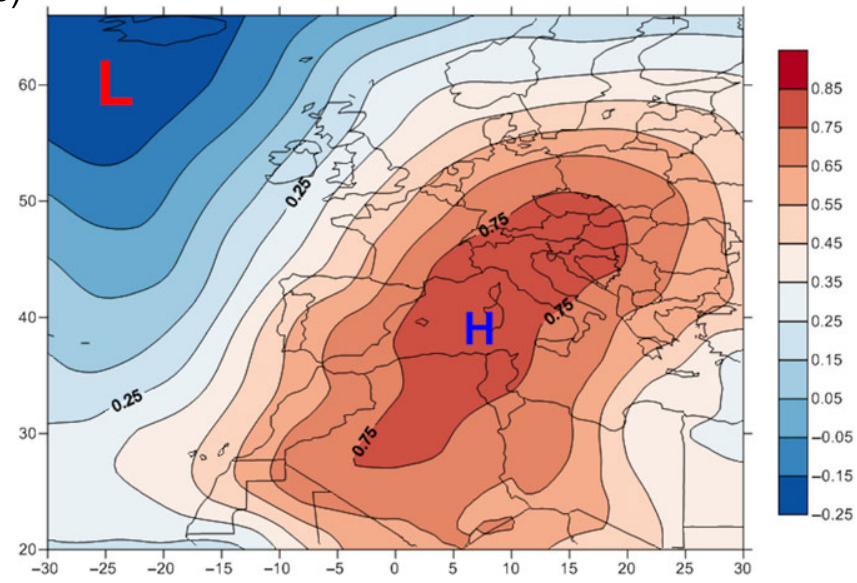

(d)

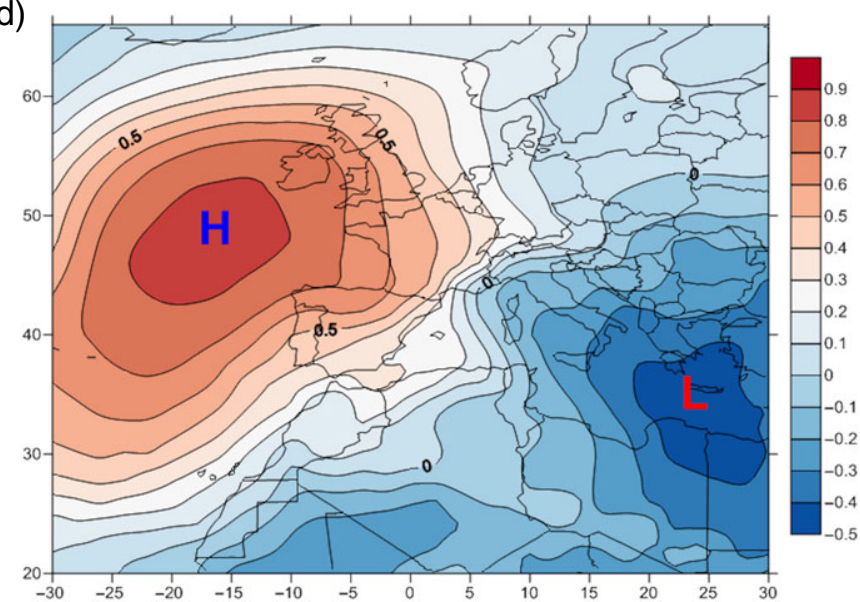

(f)

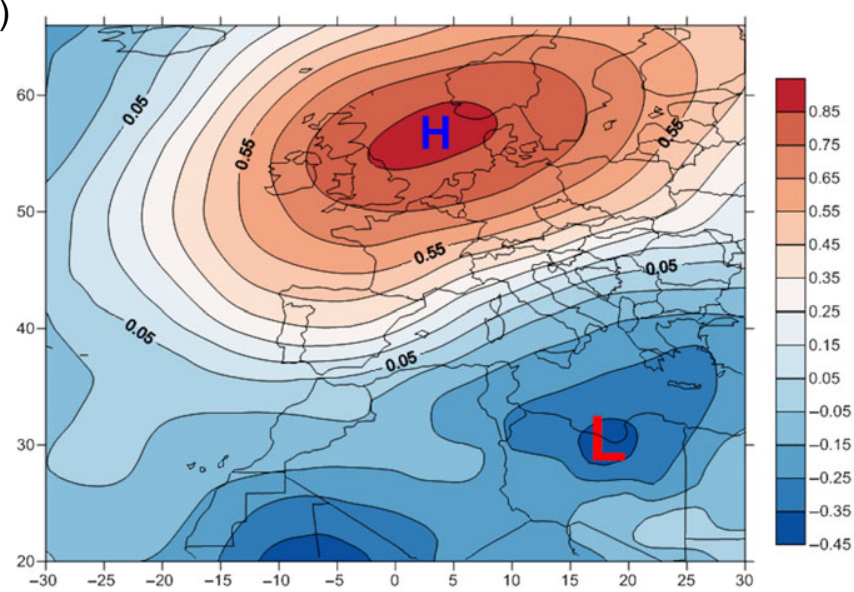

FIGURE 8 Correlation pattern for the hot episodes obtained in the S-mode for (a) m.s.l. pressure, (b) geopotential height at 850 hPa, (c) geopotential height at $700 \mathrm{hPa}$, corresponding to the first component (PC1). Correlation patterns obtained in the S-mode for (d) m.s.l. pressure, (e) geopotential height at 850 hPa, (f) geopotential height at $700 \mathrm{hPa}$, corresponding to the second component (PC2). Loading values in T-mode obtained for PC1: (g) m.s.l. pressure,

(h) geopotential height at $850 \mathrm{hPa}$, (i) geopotential height at $700 \mathrm{hPa}$, and PC2: (j) m.s.l. pressure, (k) geopotential height at $850 \mathrm{hPa}$, (1) geopotential height at $700 \mathrm{hPa}$ [Colour figure can be viewed at wileyonlinelibrary.com]

encompassing southern Europe and Northwestern Africa (Figure 9a,b). There were also strong but negative correlations in the North Atlantic Ocean, south of Iceland. A similar configuration showed the correlation map at $700 \mathrm{hPa}$ (Figure 9c). In the second component (PC2), the most positively correlated region was northern Europe (British Islands and Scandinavia), while the region with negative correlations covered North Africa and included the IP, although with low values (Figure 9d-f). These two configurations associated with PC1 and $\mathrm{PC} 2$ correspond to the two main mechanisms leading to cold spells in the IP: the first one (PC1) affecting southern Europe, Mediterranean regions and northern Africa, and the 
(g)

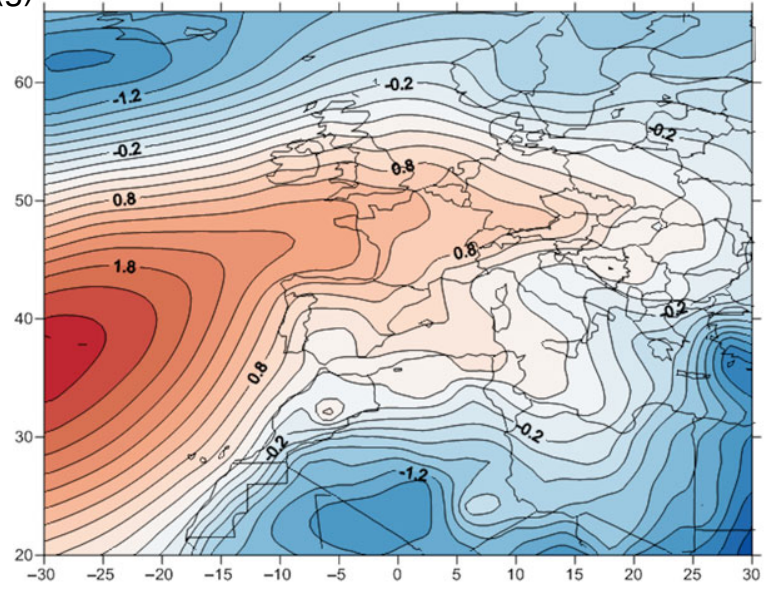

(i)

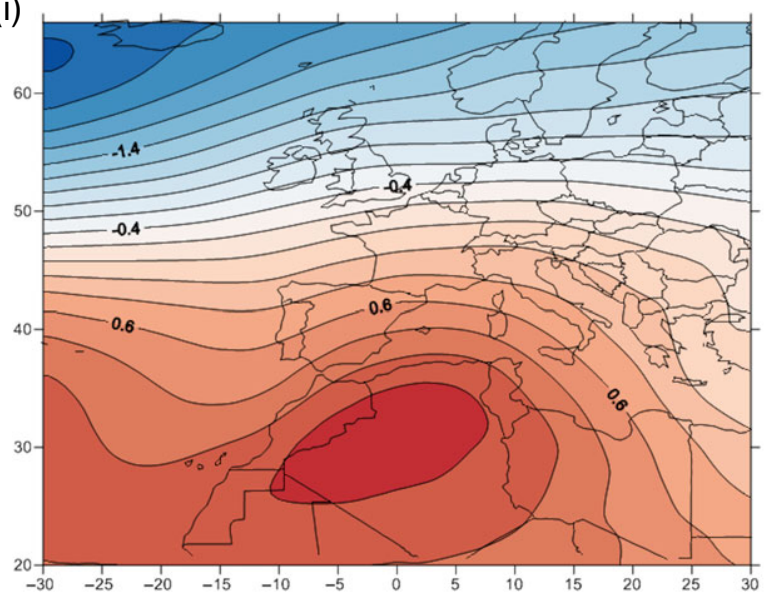

(k)

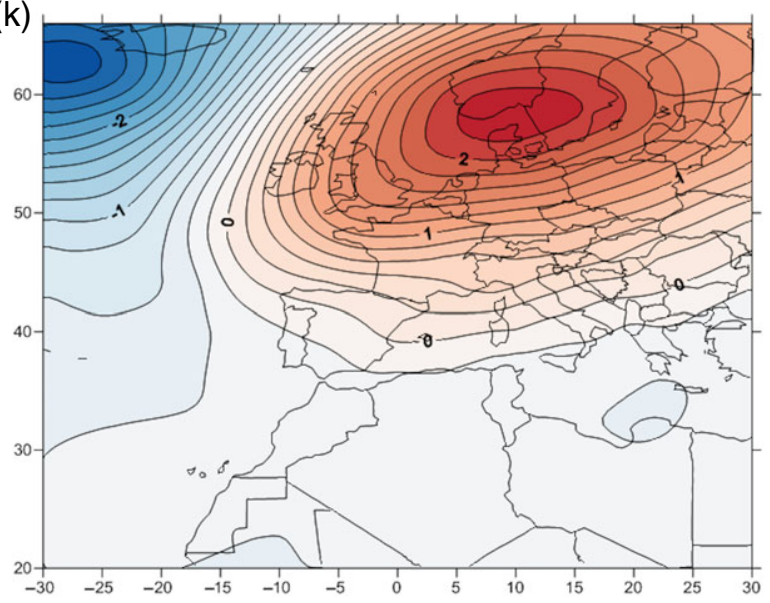

(h)

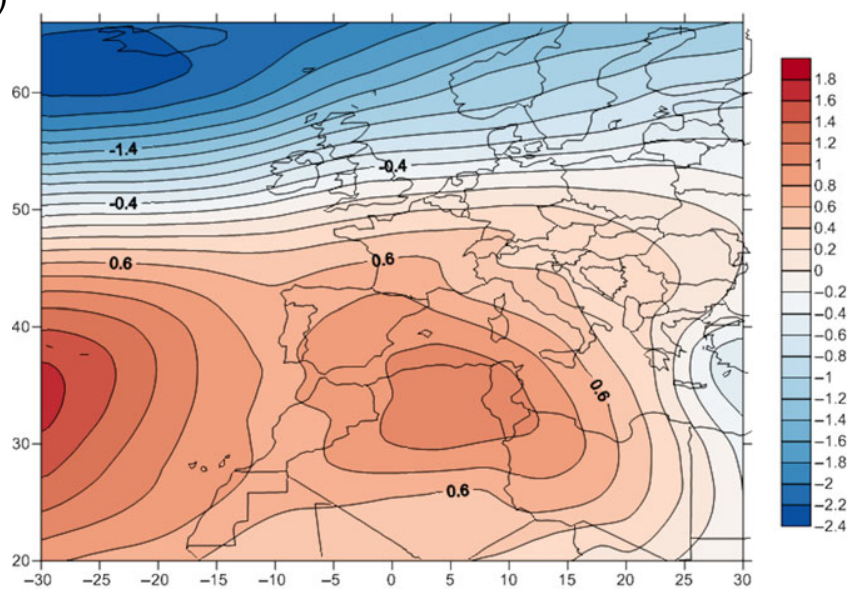

(j)

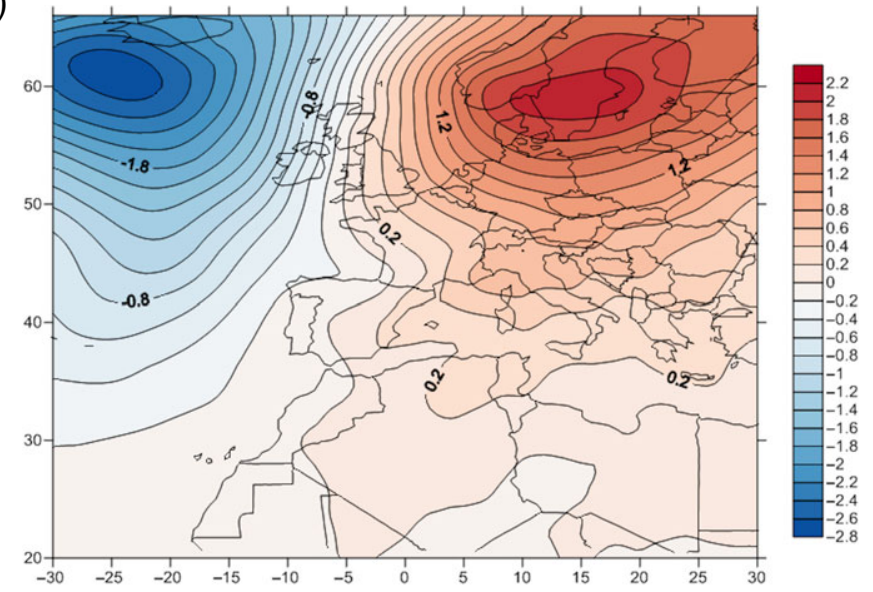

(I)

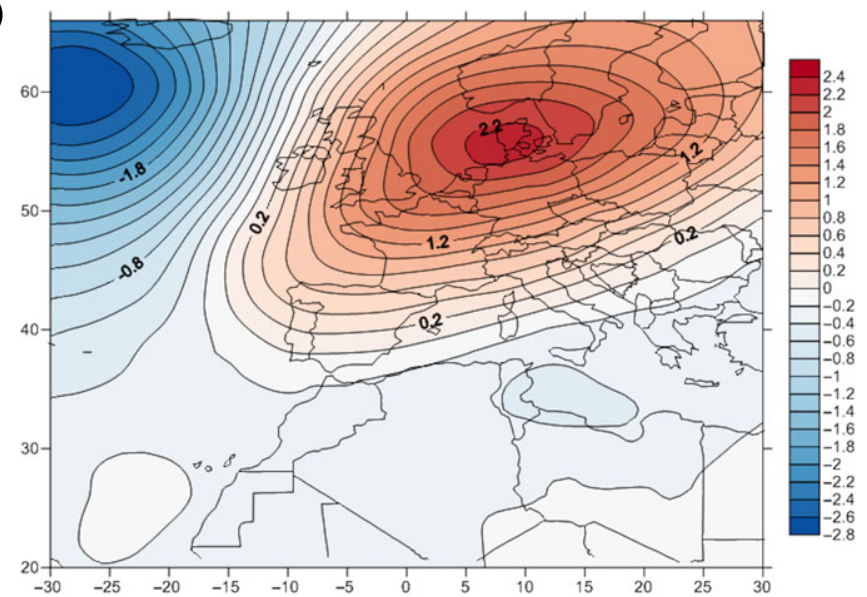

FIGURE 8 Continued

second one (PC2) affecting central and northern Europe and more tangentially the southern regions. These mechanisms are identified in the following T-mode analysis.

The first and second PC in T-mode represented $50 \%$ of the total cumulative variance. The representation of the loading values corresponding to $\mathrm{PC} 1$ shows m.s.l. pressure characterized by the presence of a high system centred over western Europe, inhibiting the westerly flow over the IP and displacing it to higher latitudes (Figure 9g). At $850 \mathrm{hPa}$, a trough appears and becomes more clearly visible at $700 \mathrm{hPa}$ (Figure 9h,i), with its axis crossing central Europe from the northeast to southwest and inducing a northern circulation over the IP. The circulation obtained from the second component (PC2, Figure 9j-1) is dominated by a dipole whose centres are in the North Atlantic (south of Iceland) and the Ligurian Sea, generating a north-easterly flow from Scandinavia and Siberia to the IP. The presence of the North Atlantic high-pressure system is in agreement with different 
(b)
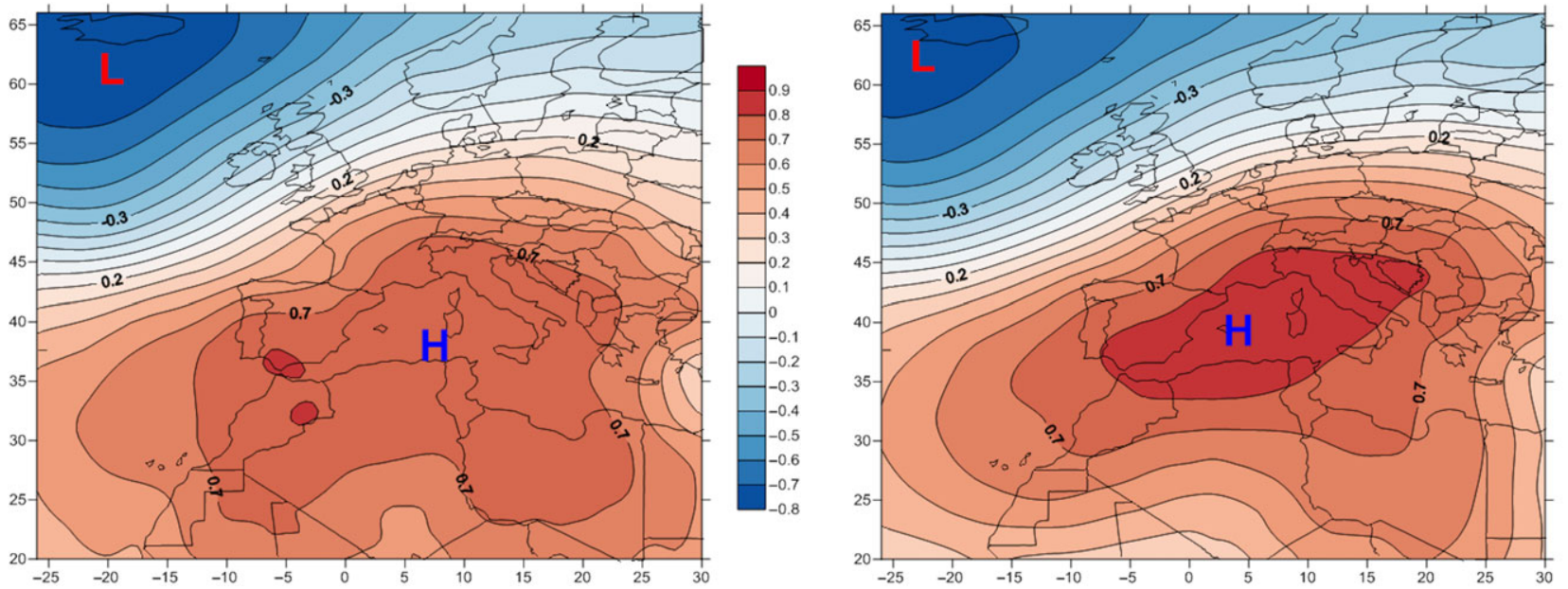

(c)
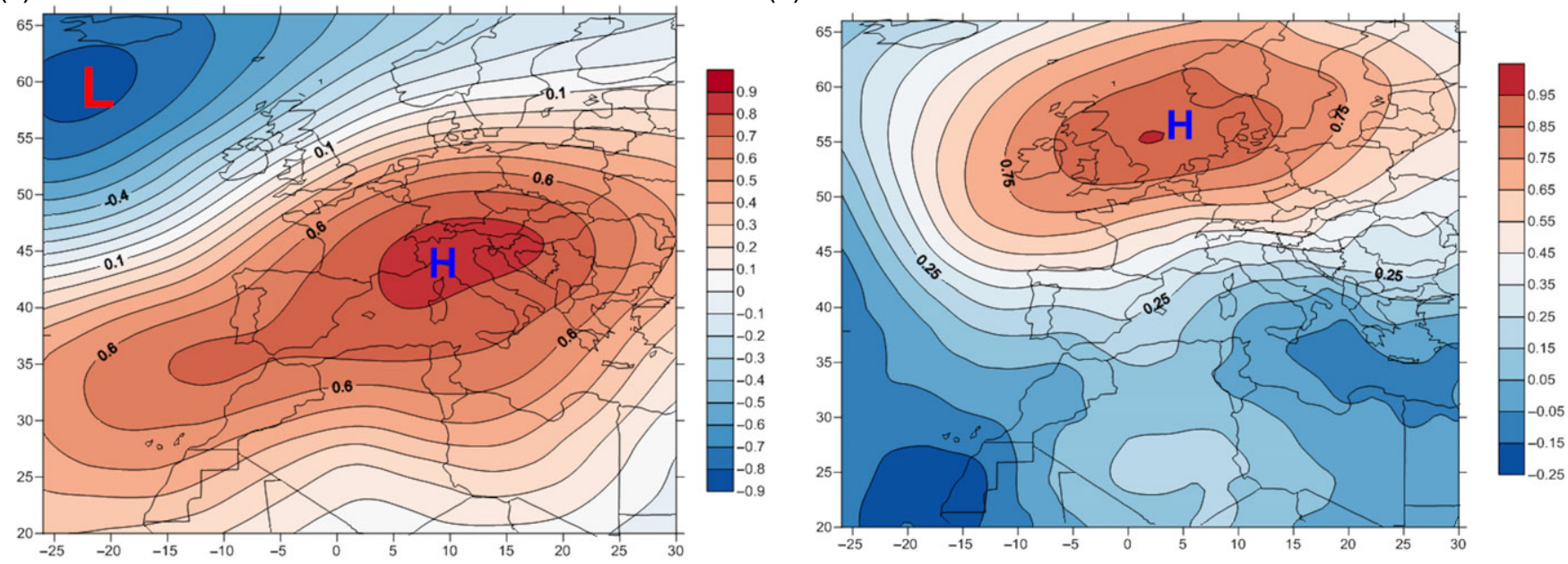

(e)

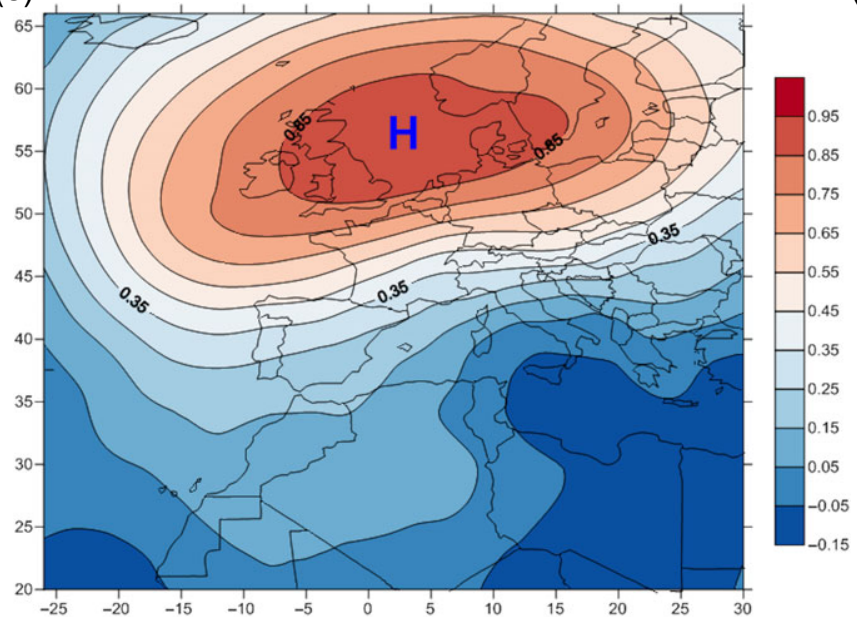

(f)

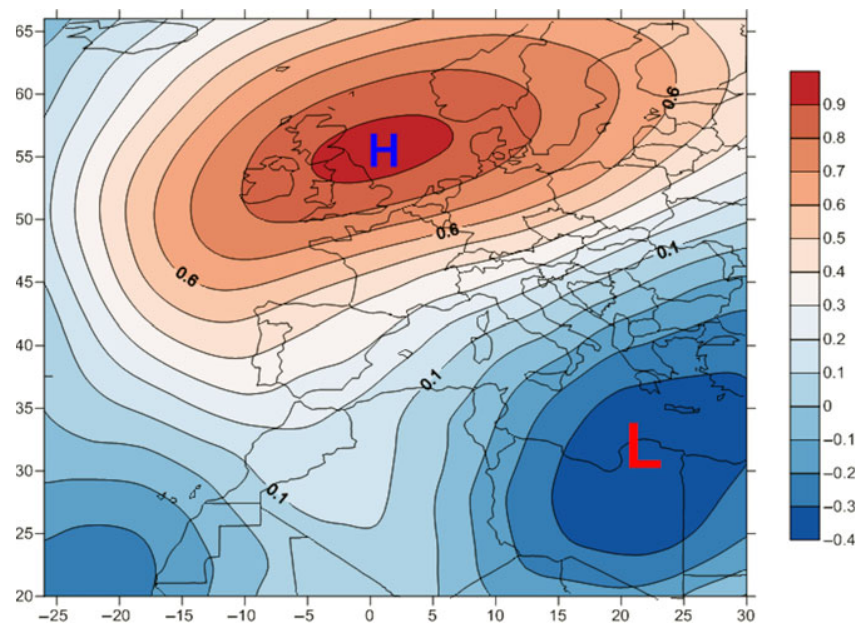

FIGURE 9 Same as Figure 8, but for cold events [Colour figure can be viewed at wileyonlinelibrary.com]

works (Walsh et al., 2001; Buehler et al., 2011; Sillmann et al., 2011). These authors suggest a close connection between eastern North Atlantic blocking and cold extremes in Europe, induced by the northerly advection on the eastern flow of the block (Pfahl and Wernli, 2012).
The analysis in T-mode concurs with that of S-mode, indicating that southern Europe and the Mediterranean are the regions more sensitive to Polar air-mass intrusions, while northern, western and central Europe are sensitive to the western Siberian fluxes. 
(g)

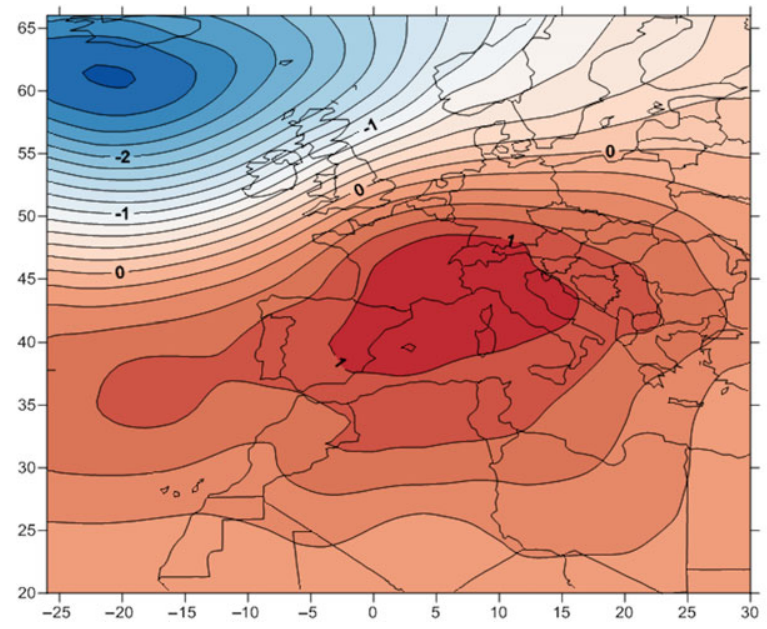

(i)

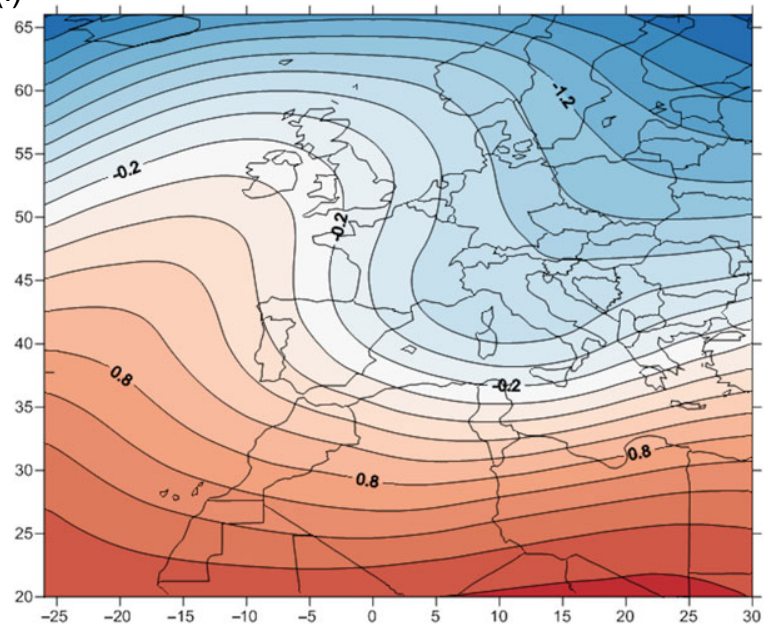

(k)

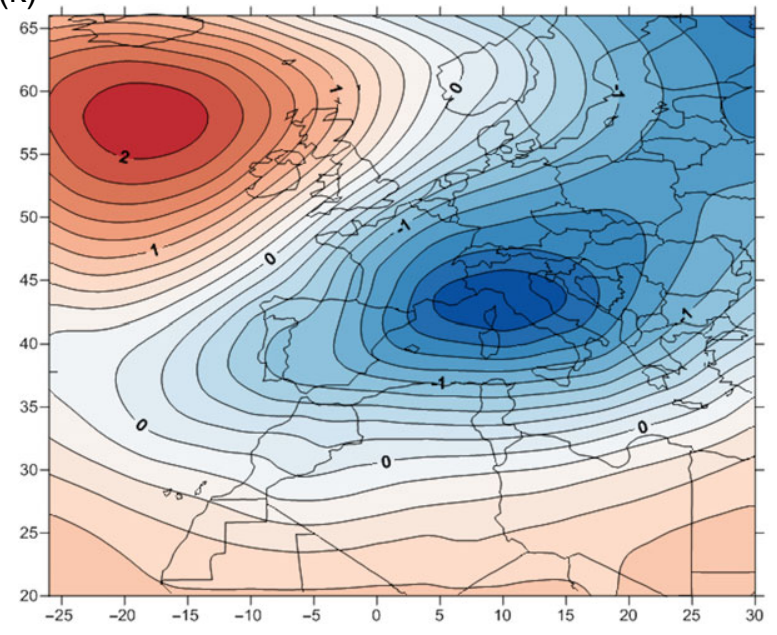

FIGURE 9 Continued

\section{4 | SUMMARY AND CONCLUSIONS}

The mechanisms underlying the occurrence of extreme hot and cold events for the 20-year period 1994-2013 in the IP have been analysed using a Lagrangian approach. The synoptic conditions during the events have been characterized using PCA of the m.s.l. pressure and geopotential fields at (h)

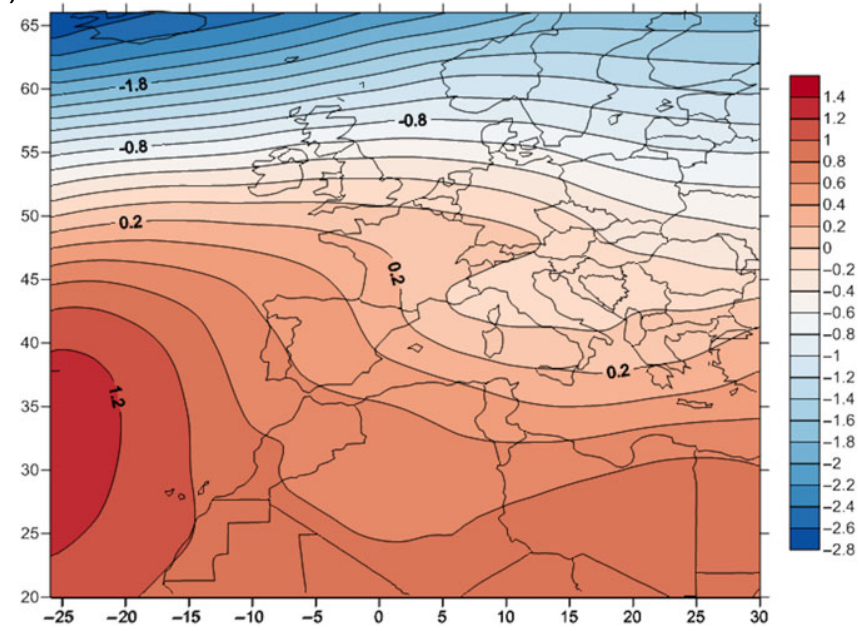

(j)

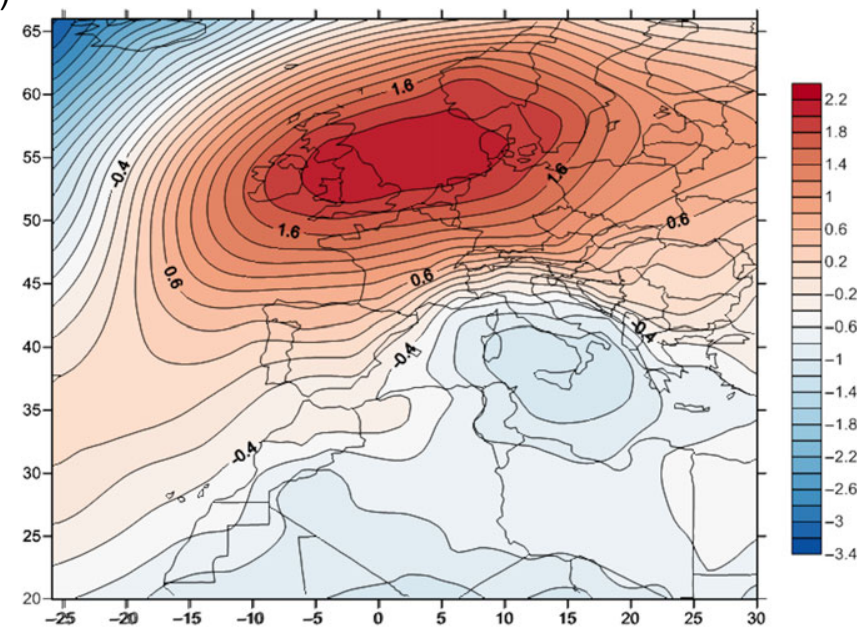

(I)

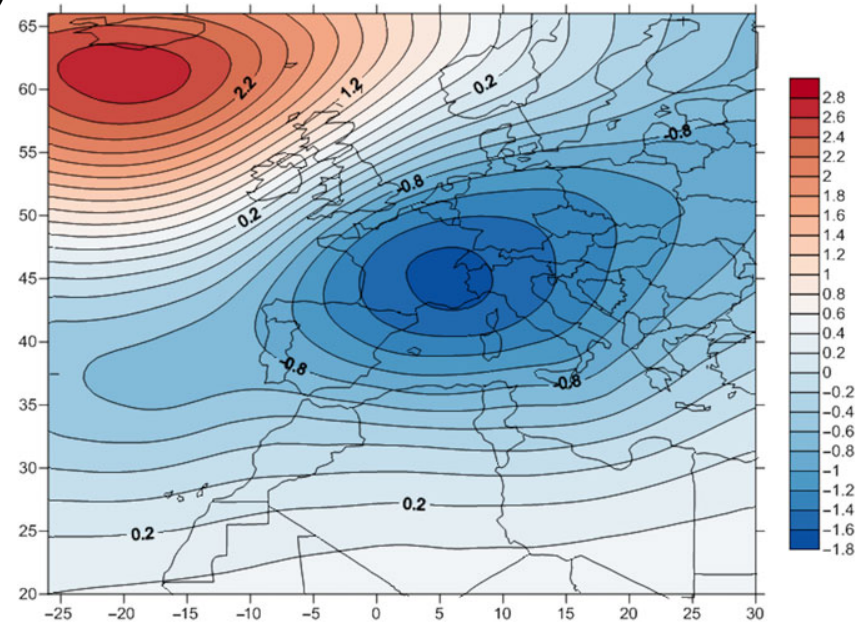

850 and $700 \mathrm{hPa}$. The hot/cold episodes were selected based on the $99.9 \mathrm{th} / 0.1$ th percentile of the $2 \mathrm{~m}$ height temperature from the ERA-Interim reanalysis data.

The study shows that there is a positive trend in the occurrence and persistence of both hot and cold events, with the slope of the trending lines being more pronounced for the period comprising the last 10 years. 
The analysis of the influence of the main climatic patterns affecting southern Europe showed that the annual number of cold extremes correlated negatively $(p<.01)$ with $\mathrm{NAO}$ and $\mathrm{AO}$ annual indices, indicating that in years of positive (negative) NAO and/or AO, the production of cold extremes is lower (higher). On the other hand, a significant positive correlation $(p<.01)$ was found between annual WeMO and the annual average temperature of hot events. Then, in years with a positive WeMO phase, the values of the extreme hot temperatures are higher, and vice versa.

No important meridional advection is involved in the production of hot extremes. Most of the back trajectories remained within the IP and its close surroundings during the 2 or 3 days prior to the hot events. The evolution of the physical variables indicated that the occurrence of hot extremes was due to diabatic warming caused by air masses of long residence time over the IP and to recirculation processes on summer days of weak baric gradient. The entrance of Saharan warm air masses from northern Africa seems to have less relevance and a more occasional character, as in the case of the August 2003 extreme temperatures.

Cold event back trajectories were faster than those of hot events, and they were mainly associated with the advection of air masses from northeast and northern Europe. The evolution of the median temperature versus median potential temperature showed that in the first days the air masses experienced diabatic radiative cooling during their passage through the high latitude regions. This was followed by adiabatic warming due to subsidence, which was persistent until the start of the episodes.

While synoptic situations control the occurrence of cold events, hot events seem to be driven by mesoscale characteristics. This could explain why the persistence of cold events reaches the maximum frequency in 2 days, while for hot events this occurs in 1 day. However, there are a similar number of cold and hot episodes with a persistence of between 1 and 3 days, about $80 \%$.

The PCA of the pressure and geopotential fields revealed two synoptic configurations causing cold air masses to enter the IP: the first one was associated with the presence of an anticyclonic system over central and northern Europe at low levels, as well as a trough in height. This configuration induces Polar winds over southern Europe and the western Mediterranean. The second configuration corresponds to the formation of a blocking dipole with centres over the North Atlantic (south of Iceland Scandinavia or Northwestern Russia) and central Europe. It impels northeasterly winds from the Siberian region to Western Europe. This configuration, with a blocking system in the North Atlantic, has been widely associated with the occurrence of European winter cold extremes, characterized by subsidence westward trajectories involving the retardation and/or reversal of the North Atlantic westerlies impinging upon Europe.
To better understand the mechanisms leading to extreme temperatures in the IP, a future work will focus on analysing specific extreme cases. It would be interesting to analyse episodes that simultaneously affect most of the grid points, and others that affect only a small number of points, in order to determine the differences in the physical mechanisms leading to these situations. In the present study, we have focused on the synoptic scale; however, a more accurate characterization would be provided through an analysis of specific situations using a mesoscale model such as the Weather Research and Forecasting model.

\section{ACKNOWLEDGEMENTS}

The authors would like to acknowledge the financial support from the Spanish Government through the projects CGL2012-39523-C02-01/CLI, CGL2012-39523-C02-02, CGL2012-37416-C04-03, CGL2016-75996-R and CTM2017-89565-C2-2-P. A.J.M. wishes to thank the Iraqi Ministry of Higher Education and Scientific Research and Al-Mustansiriya University for their support in carrying out this research. The authors would also like to thank the European Centre for Medium-Range Weather Forecasts for making freely available the ERA13 Interim reanalysis; J. Tuset (University of Lleida) for producing Figure 1; I. Bladé (University of Barcelona) for providing the summer NAO index data and J. Martín-Vide and J. A. López-Bustins (University of Barcelona) for the WeMO index data.

\section{ORCID}

Ali J. Mohammed (D) http://orcid.org/0000-0001-7482-342X

Marta Alarcón (D) http://orcid.org/0000-0002-0938-6873

David Pino (D) http://orcid.org/0000-0002-4512-0175

\section{REFERENCES}

Alexander, L.V., Zhang, X., Peterson, T.C., et al. (2006) Global observed changes in daily climate extremes of temperature and precipitation. Journal of Geophysical Research: Atmospheres, 111, D05109, https://doi.org/10. 1029/2005JD006290.

Andrade, C., Leite, S.M. and Santos, J.A. (2012) Temperature extremes in Europe: overview of their driving atmospheric patterns. Natural Hazards and Earth System Sciences, 12, 1671-1691.

Bieli, M., Pfahl, S. and Wernli, H. (2014) A lagrangian investigation of hot and cold temperature extremes in Europe. Quarterly Journal of the Royal Meteorological Society, 141, 98-108.

Bladé, I., Liebmann, B., Fortuny, D. and Van Oldenborgh, G.J. (2011) Observed and simulated impacts of the summer NAO in Europe: implications for projected drying in the Mediterranean region. Climate Dynamics, 39, 709-727.

Brunet, M., Jones, P.D., Sigró, J., Saladié, O., Aguilar, E., Moberg, A., Della-Marta, P.M., Lister, D., Walther, A. and Lopez, D. (2007) Tempora and spatial temperature variability and change over Spain during 1850-2005. Journal of Geophysical Research, 112, 28-D12117.

Buehler, T., Raible, C.C. and Stocker, T.F. (2011) The relationship of winter season North Atlantic blocking frequencies to extreme cold or dry spells in the ERA-40. Tellus Series A, 63, 212-222. https://doi.org/10.1111/j.1600-0870. 2010.00492.x.

Castro-Díez, Y., Esteban-Parra, M.J., Staudt, M. and Gámiz-Fortis, S. (2007) Temperature and precipitation changes in Andalusia in the Iberian Peninsula and Northern Hemisphere context. In: Sousa, A. , García-Barrón, L. and 
Jurado, V. (Eds.) Climate Change in Andalusia: Trends and Environmental Consequences. Spain: Consejería de Medio Ambiente (Junta de Andalucía).

Cattiaux, J., Vautard, R., Cassou, C., Yiou, P., Masson-Delmotte, V. and Codron, F. (2010) Winter 2010 in Europe: a cold extreme in a warming climate. Geophysical Research Letters, 37, L20704, https://doi.org/10.1029/ 2010GL044613.

Cattiaux, J., Yiou, P. and Vautard, R. (2012) Dynamics of future seasonal temperature trends and extremes in Europe: a multimodel analysis from CMIP3. Climate Dynamics, 38, 1949-1964.

Compagnucci, R.H., Araneo, D. and Canziani, P.O. (2001) Principal sequence pattern analysis: a new approach to classifying the evolution of atmospheric systems. International Journal of Climatology, 21, 197-217.

Cooney, C.M. (2012) Managing the risks of extreme weather: IPCC special report. Environmental Health Perspectives, 120, a58.

Croci-Maspoli, M., Schwierz, C. and Davies, H.C. (2007) Atmospheric blocking: space-time links to the NAO and PNA. Climate Dynamics, 29, 713-725.

Dankers, R. and Hiederer, R. (2008) Extreme Temperatures and Precipitation in Europe: Analysis of a High-Resolution Climate Change Scenario. Luxembourg, Europe: Office for Official Publications of the European Communities, p. 23291.

Del Río, S., Herrero, L., Pinto-Gomes, C. and Penas, A. (2011) Spatial analysis of mean temperature trends in Spain over the period 1961-2006. Global and Planetary Change, 78, 65-75.

Della-Marta, P.M., Luterbacher, J., von Weissenfluh, H., Xoplaki, E., Brunet, M. and Wanner, H. (2007) Summer heat waves over Western Europe 1880-2003, their relationship to large-scale forcings and predictability. Climate Dynamics, 29, 251-275.

Draxler, R.R. and Rolph, G.D. (2003) HYSPLIT (HYbrid Single-Particle Lagrangian Integrated Trajectory) Model Access via NOAA ARL READY Website (http://www.arl.noaa.gov/ ready/hysplit4.html). Silver Spring, MD: NOAA Air Resources Laboratory.

Efthymiadis, D., Goodess, C.M. and Jones, P.D. (2011) Trends in Mediterranean gridded temperature extremes and large-scale circulation influences. Natural Hazards and Earth System Sciences, 11, 2199-2214.

El Kenawy, A., López-Moreno, J.I. and Vicente-Serrano, S.M. (2013) Summer temperature extremes in northeastern Spain: spatial regionalization and links to atmospheric circulation (1960-2006). Theoretical and Applied Climatology, 113, 387-405.

Favà, V., Curto, J.J. and Llasat, M.C. (2016) Relationship between the summer $\mathrm{NAO}$ and maximum temperatures for the Iberian Peninsula. Theoretical and Applied Climatology, 126, 77-91.

Fernández-Montes, S., Rodrigo, F.S., Seubert, S. and Sousa, S. (2013) Spring and summer extreme temperatures in Iberia during last century in relation to circulation types. Atmospheric Research, 127, 154-177.

Frich, P., Alexander, L.V., Della-Marta, P., Gleason, B., Haylock, M., Tank, A. K. and Peterson, T. (2002) Observed coherent changes in climatic extremes during the second half of the twentieth century. Climate Research, 19, 193-212.

Furió, D. and Meneu, V. (2011) Analysis of extreme temperatures for four sites across Peninsular Spain. Theoretical and Applied Climatology, 104, 83-99.

Harsant, J., Pavlovic, L., Chiu, G., Sultmanis, S. and Sage, T.L. (2013) High temperature stress and its effect on pollen development and morphological components of harvest index in the $\mathrm{C} 3$ model grass Brachypodium distachyon. Journal of Experimental Botany, 64, 2971-2983. https://doi.org/10. 1093/jxb/ert142.

Hoinka, K.P. and Castro, M.D. (2003) The Iberian Peninsula thermal low. Quarterly Journal of the Royal Meteorological Society, 129, 1491-1511.

Horton, D.E., Singh, J.D., Swain, D.L., Rajaratnam, B. and Diffenbaugh, N.S. (2015) Contribution of changes in atmospheric circulation patterns to extreme temperature trends. Nature, 522, 465-471.

Hurrell, J.W., Kushnir, Y., Visbeck, M. and Ottersen, G. (2013) An overview of the North Atlantic Oscillation. In: Hurrell, J.W., Kushnir, Y., Visbeck, M. and Ottersen, G. (Eds.) The North Atlantic Oscillation: Climate Significance and Environmental Impact. Geophysical Monograph Series. Washington, DC: American Physical Union, pp. 1-35.

Huth, R. (1996) An intercomparison of computer-assisted circulation classification methods. International Journal of Climatology, 16, 893-922.

IPCC. (2013) Climate change 2013: the physical science basis. In: Stocker, T.F., Qin, D., Plattner, G.-K., Tignor, M., Allen, S.K., Boschung, J., Nauels, A., Xia, Y., Bex, V. and Midgley, P.M. (Eds.) Contribution of Working Group I to the Fifth Assessment Report of the Intergovernmental Panel on Climate
Change. Cambridge, UK and New York, NY: Cambridge University Press, p. 1535. https://doi.org/10.1017/CBO9781107415324.

Izquierdo, R., Aguillaume, L., Alarcón, M. and Avila, A. (2014) Effects of teleconnection patterns on the atmospheric routes, precipitation amount and chemistry in the north-eastern Iberian Peninsula. Atmospheric Environment, $89,482-490$.

Izquierdo, R., Alarcón, M., Periago, C. and Belmonte, J. (2015) Is long range transport of pollen in the NW Mediterranean basin influenced by Northern Hemisphere teleconnection patterns? Science of the Total Environment, 532, 771-779.

Jorba, O., Pérez, C., Rocadensbosch, F. and Baldasano, J.M. (2004) Cluster analysis of 4-day back trajectories arriving in the Barcelona area, Spain, from 1997 to 2002. Journal of Applied Meteorology, 43, 887-901.

Jung, T., Vitart, F., Ferranti, L. and Morcrette, J.J. (2011) Origin and predictability of the extreme negative NAO winter of 2009/10. Geophysical Research Letters, 38, L07701, https://doi.org/10.1029/2011GL046786.

Katz, R.W. and Brown, B.G. (1992) Extreme events in a changing climate: variability is more important than averages. Climatic Change, 21, 289-302.

Kebede, A.S., Dunford, R., Mokrech, M., Audsley, E., Harrison, P.A., Holman, I.P., Nicholls, R.J., Rickebusch, S., Rounsevell, M.D.A., Sabate, S., Sallaba, F., Sanchez, A., Savin, C., Trnka, M. and Wimmer, F. (2015) Direct and indirect impacts of climate and socio-economic change in Europe: a sensitivity analysis for key land- and water-based sectors. Climatic Change, 128, 261-277.

López-Bustins, J.A., Martín-Vide, J. and Sanchez-Lorenzo, A. (2008) Iberia winter rainfall trends based upon changes in teleconnection and circulation patterns. Global and Planetary Change, 63, 171e176.

Luterbacher, J., Dietrich, D., Xoplaki, E., Grosjean, M. and Wanner, H. (2004) European seasonal and annual temperature variability, trends, and extremes since 1500. Science, 303, 499-1503.

Martín-Vide, J. and López-Bustins, J.A. (2006) The Western Mediterranean Oscillation and rainfall in the Iberian Peninsula. International Journal of Climatology, 26(11), 1455-1475.

Millán, M.M., Artíñano, B., Alonso, L.A., Navazo, M. and Castro, M. (1991) The effect of meso-scale flows on regional and long-range atmospheric transport in the western Mediterranean area. Atmospheric Environment, 25, 949-963.

Millán, M.M., Salvador, R., Mantilla, E. and Kallos, G. (1997) Photo-oxidant dynamics in the Mediterranean basin in summer: results from European research projects. Journal of Geophysical Research, 102, 8811-8823.

Pfahl, S. and Wernli, H. (2012) Quantifying the relevance of atmospheric blocking for co-located temperature extremes in the Northern Hemisphere on (sub-) daily time scales. Geophysical Research Letters, 39, L12807.

Prieto, L., Herrera, R.G., Díaz, J., Hernández, E. and Del Teso, T. (2004) Minimum extreme temperatures over Peninsular Spain. Global and Planetary Change, 44, 59-71.

Rodrigo, F.S. (2015) On the covariability of seasonal temperatures and precipitation in Spain, 1956-2005. International Journal of Climatology, 35, 3362-3370.

Rodríguez-Puebla, C., Encinas, A.H., García-Casado, L.A. and Nieto, S. (2010) Trends in warm days and cold nights over the Iberian Peninsula: relationships to large-scale variables. Climatic Change, 100, 667-684.

Sáenz, J., Zubillaga, J. and Rodríguez-Puebla, C. (2001) Interannual winter temperature variability in the north of the Iberian Peninsula. Climate Research, $16,169-179$.

Schindler, D.W. (1997) Widespread effects of climatic warming on freshwater ecosystems in North America. Hydrological Processes, 11, 1043-1067.

Schönwiese, C.D. and Rapp, J. (1997) Climate Trend Atlas of Europe Based on Observations 1891-1990, Vol. 235. Dordrecht: Kluwer Academic publishers.

Serra, C., Burgueño, A. and Lana, X. (2001) Analysis of maximum and minimum daily temperatures recorded at Fabra Observatory (Barcelona, NE Spain) in the period 1917-1998. International Journal of Climatology, 21, 617-636.

Sillmann, J., Croci-Maspoli, M., Kallache, M. and Katz, R.W. (2011) Extreme cold winter temperatures in Europe under the influence of North Atlantic atmospheric blocking. Journal of Climate, 24, 5899-5913.

Steyn, D.G. (1998) Scaling the vertical structure of sea breezes. Boundary-Layer Meteorology, 86, 505-524. https://doi.org/10.1023/A:1000743222389.

Stohl, A. (1998) Computation, accuracy and applications of trajectories - a review and bibliography. Atmospheric Environment, 32, 947-966. 
Tomassini, L., Gerber, E.P., Baldwin, M.P., Bunzel, F. and Giorgetta, M. (2012) The role of stratosphere-troposphere coupling in the occurrence of extreme winter cold spells over northern Europe. Journal of Advances in Modeling Earth Systems, 4, M00A03, https://doi.org/10.1029/2012MS000177.

Trigo, R.M., Trigo, J.F., DaCamara, C.C. and Osborn, T.J. (2004) Climate impact of the European winter blocking episodes from NCEP/NCAR Reanalyses. Climate Dynamics, 23, 17-28. https://doi.org/10.1007/s00382-004-0410-4.

Tullot, I.F. (2000) Climatologia de España y Portugal (Vol. 76). Spain , Salamanca: Universidad de Salamanca.

Vicente-Serrano, S.M., Beguería, S., López Moreno, J.I., El Kenawy, A. and Angulo, M.M. (2009) Daily atmospheric circulation events and extreme precipitation risk in northeast Spain: role of the North Atlantic Oscillation, the Western Mediterranean Oscillation, and the Mediterranean Oscillation. Journal of Geophysical Research, 114, D08106. https://doi.org/10.1029/2008JD011492.
Walsh, J.E., Phillips, A.S., Portis, D.H. and Chapman, W.L. (2001) Extreme cold outbreaks in the United States and Europe, 1948-99. Journal of Climate, 14, 2642-2658.

How to cite this article: Mohammed AJ, Alarcón M, Pino D. Extreme temperature events on the Iberian Peninsula: Statistical trajectory analysis and synoptic patterns. Int J Climatol. 2018;1-18. https://doi.org/10.1002/joc.5733 


\title{
Graphical abstract
}

\section{Extreme temperature events on the Iberian Peninsula: Statistical trajectory analysis and synoptic patterns}

\author{
Ali J. Mohammed, Marta Alarcón, and David Pino
}
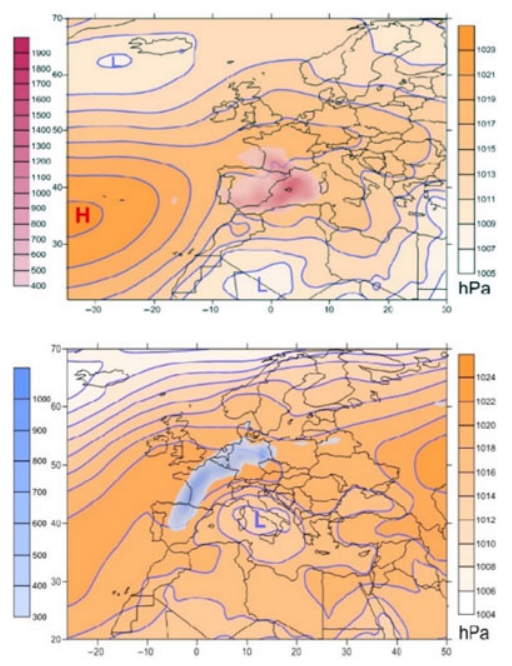

The primary cause of occurrence of hot extremes in Iberian Peninsula (IP) is a progressive diabatic warming caused by air masses with long residence times over the IP and by recirculation processes during summer days of weak baric gradient. The extreme cold events are associated with air-mass advection from north and northeast Europe, induced by the presence of a relative low in the central Mediterranean and a blocking high in the North Atlantic and/or in north-eastern Europe. 